\title{
Seismic Performance Assessment of High Asphalt Concrete Core Rockfill Dam Considering Shorter Duration and Longer Duration
}

benbo sun

Tianjin University

Mingjiang Deng

Xinjiang Ertix River Basin Development and Construction Management Bureau

Sherong Zhang

Tianjin University

Chao Wang ( $\square$ janson126@163.com )

Tianjin university https://orcid.org/0000-0003-1853-2833

Guojin Zhu

Kunming Engineering Corporation Limited

\section{Research Article}

Keywords: Integrated duration, Asphalt concrete core rockfill dam, Fragility analysis, Performance level, Multiple stripe analysis

Posted Date: June 1st, 2021

DOI: https://doi.org/10.21203/rs.3.rs-501314/v1

License: (c) (i) This work is licensed under a Creative Commons Attribution 4.0 International License. Read Full License

Version of Record: A version of this preprint was published at Structures on May 1st, 2022. See the published version at https://doi.org/10.1016/j.istruc.2022.03.040. 
1 Seismic performance assessment of high asphalt concrete core rockfill dam considering shorter

2 duration and longer duration

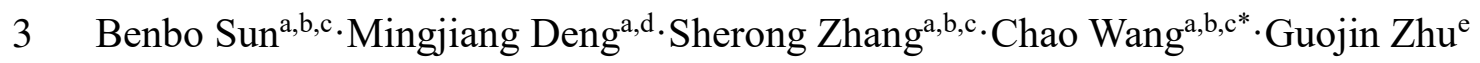

4 a State Key Laboratory of Hydraulic Engineering Simulation and Safety, Tianjin University, Tianjin

5300350, China

6 b Key Laboratory of Earthquake Engineering Simulation and Seismic Resilience of China

7 Earthquake Administration, Tianjin 300350, China;

8 c School of Civil Engineering, Tianjin University, Tianjin 300350, China

9 d Xinjiang Ertix River Basin Development and Construction Management Bureau, Urumqi 830000,

10 China

11 e POWERCHINA Kunming Engineering Corporation Limited, Kunming 650051, China

\section{Abstract}

13 Current research trends in seismic frequent regions aim at developing the appropriate

14 performance - based design approach for high asphalt concrete core rockfill dams (ACCRDs). Under

15 intense ground motions (GMs), the seismic performance of dams depends on seismological

16 characteristics mainly containing the frequency, amplitude, and duration. Recently, the characteristic

17 of frequency and amplitude of GMs which can trigger severe damages to the dams has been accepted

18 and incorporated into the seismic design codes in most countries. As one of the key characteristics of

19 earthquakes, the duration of strong GMs also should be fully understood in order to carry out more 
20 reasonable performance - based design approach of dams. This paper explores the effect of the

21 duration of strong GMs, investing the seismic performance of high ACCRDs by employing integrated

22 duration concept, which can reflect the duration of all components of GMs. The high ACCRD was

23 built in the commercial software ABAQUS considering the dam-reservoir-foundation interaction

24 systems. Additionally, the coupling multiple stripe analysis and maximum likelihood estimate method

25 are used to generate seismic fragility curves for the dam according to two damage indicators. Findings

26 from this study revealed that the longer duration GMs can give rise to higher probability of exceedance

27 (POE) of the dam than shorter duration. It is recommended that in the work of the current seismic

28 design and seismic performance evaluate, the effects of GM duration in addition to frequency and

29 amplitude should be considered.

30 Keywords: Integrated duration; Asphalt concrete core rockfill dam; Fragility analysis; Performance

31 level; Multiple stripe analysis

\section{1. Introduction}

High dams are regarded as critical components of a nation's lifeline engineering, which can

34 effectively alleviate the contradiction between water supply and demand. Over the past few decades,

35 the rapidly development of water resource has witnessed a boom and a larger number of embankment

36 dams has been constructed all over the word because of their low cost, rapid, and adaptability. Recently,

37 owing to the optimization and improvement of downstream water resources, the development and

38 construction of high dams are gradually turning to the upstream of each watershed. High asphalt

39 concrete core rockfill dams (ACCRDs) has attracted the interest of the world's dam designers in 
40 upstream water resource development (Wang et al., 2010; Wang and Höeg, 2016). The mains reason

41 for this is that the ACCRDs are situated in regions with variable climatic conditions and complex

42 geological environment, or in areas with a shortage of natural earth core material. In light of the

43 vulnerability of ACCRDs to strong ground motions (GMs), evaluating their seismic performance and

44 safety is of obvious practical importance in dam construction and operation (Baziar et al., 2009).

45 Currently, the prediction of the seismic performance of ACCRDs under GM excitation is still far

46 behind concrete dams or other types of embankment dams.

47 Earthquake disaster that have frequently occurred in recent years, containing those in Sumatra,

48 Indonesia (Mw 9.1, 2004), Wenchuan, China (Mw 7.9, 2008), Maule, Chile (Mw8.8, 2010), Tohoku,

49 Japan (Mw 9.0, 2011), continue to remind us that strong GMs may trigger devastating high dam -

50 break floods and further influence large regions downstream. The most significant particularly features

51 of GMs are propagation path of seismic waves, spatial site conditions, source mechanism, ground

52 motion duration (GMD), frequency and amplitude, each of which may plays a critical part in the

53 seismic performance assessment. Generally, the characteristic of amplitude, which is one of effective

54 engineering parameters on seismic performance assessment of structures, is illustrated by the peak

55 ground displacement (PGD), the peak ground velocity (PGV) and the peak ground acceleration (PGA).

56 Moreover, the Fourier spectrum of the GM is usually employed to reveal the frequency content.

57 Conversely, present seismic design code and analysis methodology do not directly or indirectly

58 consider the impact of GMD on the seismic performance of high ACCRDs. Besides, the length of the

59 spatial distribution of GMDs is influenced by defining methods, site conditions, basin effects and

60 rupture directivity (see Fig. 1) according to the record of Wenchuan earthquake. That is to say, if the 
62 encounter different durations of GMs during its life cycle. However, the seismic performance 63 assessment of high ACCRDs under shorter duration motions and longer duration motions have not

64 been verified.
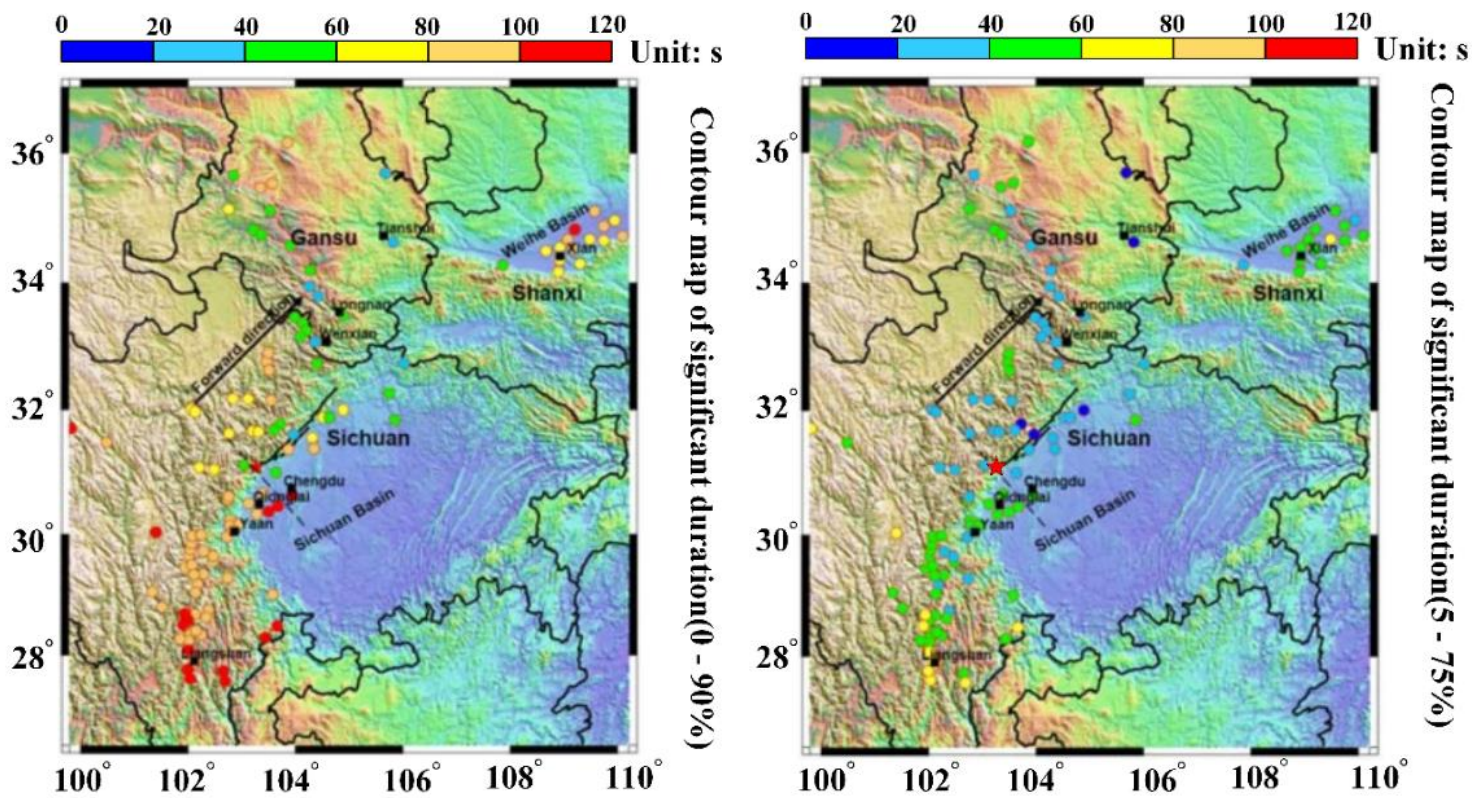

Fig. 1. Spatial distribution of significant duration recorded from Wenchuan earthquake (Mw7.9, 2008). (a) 0-90\%

71 2005). Yet, several investigations on the influence of GMD on the structural response have shown that

72 the GMD have insignificant effects on structural response. For example, Kitayama and Constantinou

73 (2020) concluded that the peak isolator resultant displacement is no stronger correlation to the GMD.

74 The relationship observed between structural response and GMD cannot be recognized uniform

75 (Raghunandan and Lie, 2013). In other words, a large number of in-depth studies are needed to reveal 
76 the influence of GMD on the structural performance for different types of structures. On the other hand,

77 some previous studies (Bommer and Martinez-Pereira, 1999; Green and Terri, 2005; Kitayama and

78 Constantinou, 2020; Ou et al., 2014; Raghunandan and Liel, 2013; Trifunac and Brady, 1975; Zhang

79 et al., 2013) on the impact of GMD on the structural performance only considering the one directional

80 GMD. Nevertheless, the duration of GMs in one direction does not fully reflect the difference of

81 duration in multi-direction. So far, it is worth noting that the definition of 30 different GMDs which

82 does not clearly consensus on the multi-direction of duration of GMs. Very recently, to bridge the gap

83 between multi-direction of GMs and duration employed for dynamic analysis, Wang et al. (2015)

84 proposed a new duration concept of integrated duration (ID) to explain the duration component

85 contributions of GMs in multi-direction. With the definition of ID, they reveal that the longer duration

86 can cause greater damage cracks for Koyna concrete dam. Because of the randomness of earthquake

87 disasters, the multi-direction of GMs have been recognized to easily trigger severe damage for high

88 dams. Understanding the effect of multi-direction of GMD on the seismic performance assessment of

89 high ACCRDs will bring the engineer one key step closer to decreasing the dam break risk.

90 Inspired by the above considerations, critical knowledge gaps exist in understanding and

91 quantifying the impact of GMD on seismic performance of high ACCRDs. Therefore, the main

92 objective of this paper is to highlight the significance of GMD for seismic performance assessment of

93 high ACCRDs considering the shorter duration and longer duration. This paper consists of six major

94 sections as follows. The basics concept and characteristic of ID is briefly reviewed in Section 2 . In

95 addition, to achieve this investigation, 30 short - and 16 long - durations of as-recorded GMs are

96 selected in Section 2, and the distribution of the GMD generated spectrally equivalent methodology 
97 are provided. The framework of seismic performance assessment is illustrated using the multiple stripe

98 analysis (MSA) and maximum likelihood estimate (MLE) with different seismic performance indices

99 in Section 3. In Section 4, the finite element (FE) numerical model for the high ACCRD is illustrated.

100 The seismic fragility analysis (FR) of the high ACCRD is discussed using the MSA - MLE with

101 different seismic performance indices in Section 5. Finally, summaries and conclusions follow in 102 Section 6.

103 2. Integrated duration and ground motion database

104 Although various definitions for GMD have been proposed to reveal the correlation between

105 GMD and the seismic performance of structures, there is still no universally recognized scientific

106 measure criterion of GMD since time history length of the accelerogram record may significantly

107 depend up on the recording device and structural performance. Among these widely differing measures,

108 the most generally applied scientific measure criterions for strong GMD can be characterized by four

109 measures including: bracketed duration $\left(T_{B}\right)$ (Bolt, 1973), uniform duration $\left(T_{v}\right)$ (Bommer et al., 2009),

110 significant duration (SD) $\left(T_{S}\right)$ (Trifunac and Brady, 1975) and effective duration $\left(T_{E}\right)$ (Bommer and

111 Martinez-Pereira, 1999). Apparently, all the aforementioned measures of GMD is generally used to

112 illustrating the duration of GMs in one direction. To be specific, the multi-direction incident seismic

113 waves brings about challenge for decouple the effect of GMD in different directions. According to the

114 concept of ID, the SD of different directions of GMs are selected as the basic component. The SD is

115 regard as an effective measure representing the duration of GMs by a relative scientific criterion. In

116 addition, the Husid diagram is determined to be the time history of the seismic energy content scaled 
117 to the total energy content (Trifunac and Brady, 1975), which satisfied the Eq. (1):

$$
H(t)=\frac{\frac{\pi}{2 g} \int_{0}^{t} a^{2}(t) d t}{I_{0}}
$$

119 where $H(t)$ is the Husid diagram defined as a function of time $t . a$ is the time history of 120 accelerogram and $g$ is the gravitational acceleration. The total Arias intensity, $I_{0}$, is obtained from

121 Eq. (2):

122

$$
I_{0}=\frac{\pi}{2 g} \int_{0}^{T_{\max }} a^{2}(t) d t
$$

123 where $T_{\text {Max }}$ is the length of the time history of accelerogram. Fig. 2 illustrates the SD of an as-record

124 strong GMs in different ranges of Arias intensity.

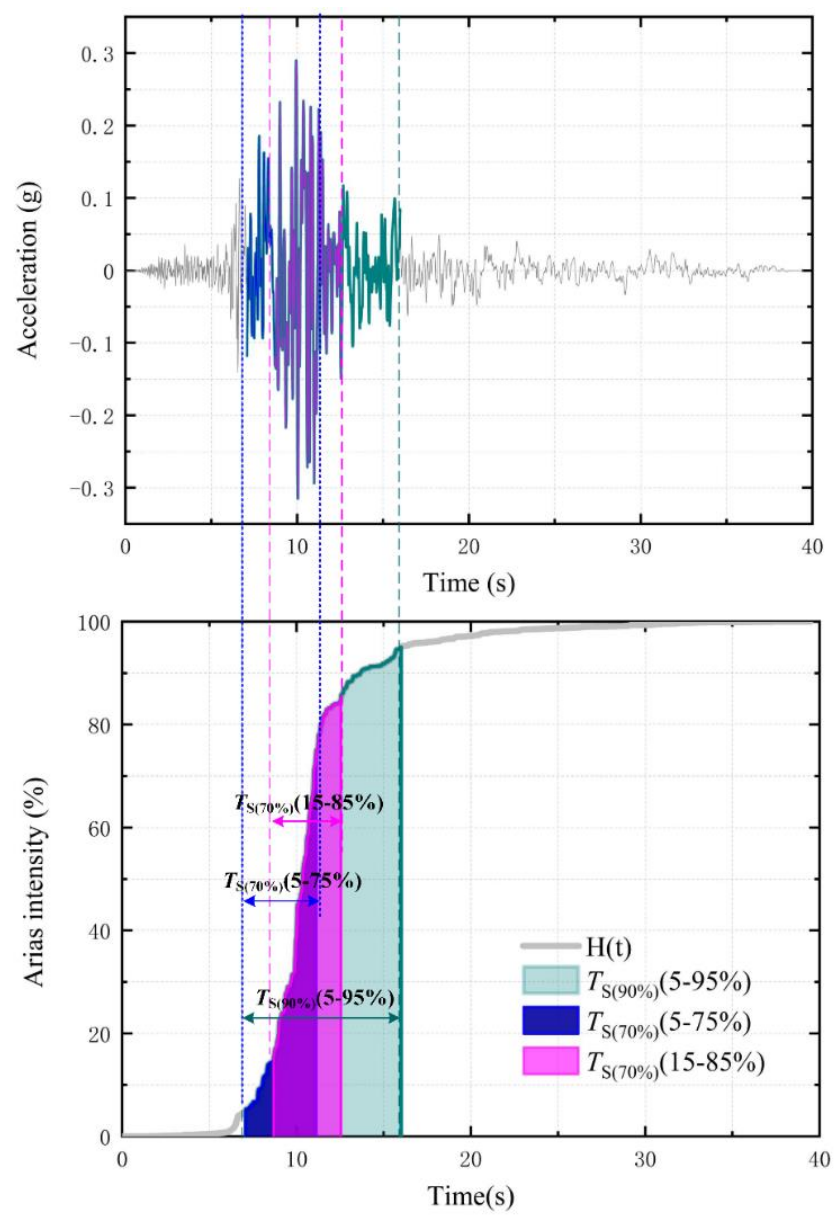

Fig. 2. The husid diagram of three SDs of an as-record accelerogram. 
128 in single direction (horizontal or vertical component). On the contrary, the ID regards the Arias

129 intensity in multi-directions as the weighting function, which is applied to weighted average the

130 corresponding single direction duration to overcome the above shortcomings. Based on the work of

131 Wang et al. (2015) the detailed formula of ID considering double directional GMs can be determined

132 as follows:

$$
T_{I}=\frac{T_{S}^{H} \times I_{0}^{H}+T_{S}^{V} \times I_{0}^{V}}{I_{0}^{H}+I_{0}^{V}}
$$

134 where $T_{S}^{H}$ and $T_{S}^{V}$ denotes the GMDs in the horizontal and vertical directions, respectively. $I_{0}^{H}$ and

$135 I_{0}^{V}$ respectively represent the horizontal Arias intensities and vertical Arias intensities of GMs. The $136 T_{S(70 \%)}(5-75 \%)$ which can be easily defined as the time gap between $5 \%$ and $75 \%$ of the Husid 137 diagram, is selected to indicate GMDs in multi-directions, as depicted in Fig. 3.

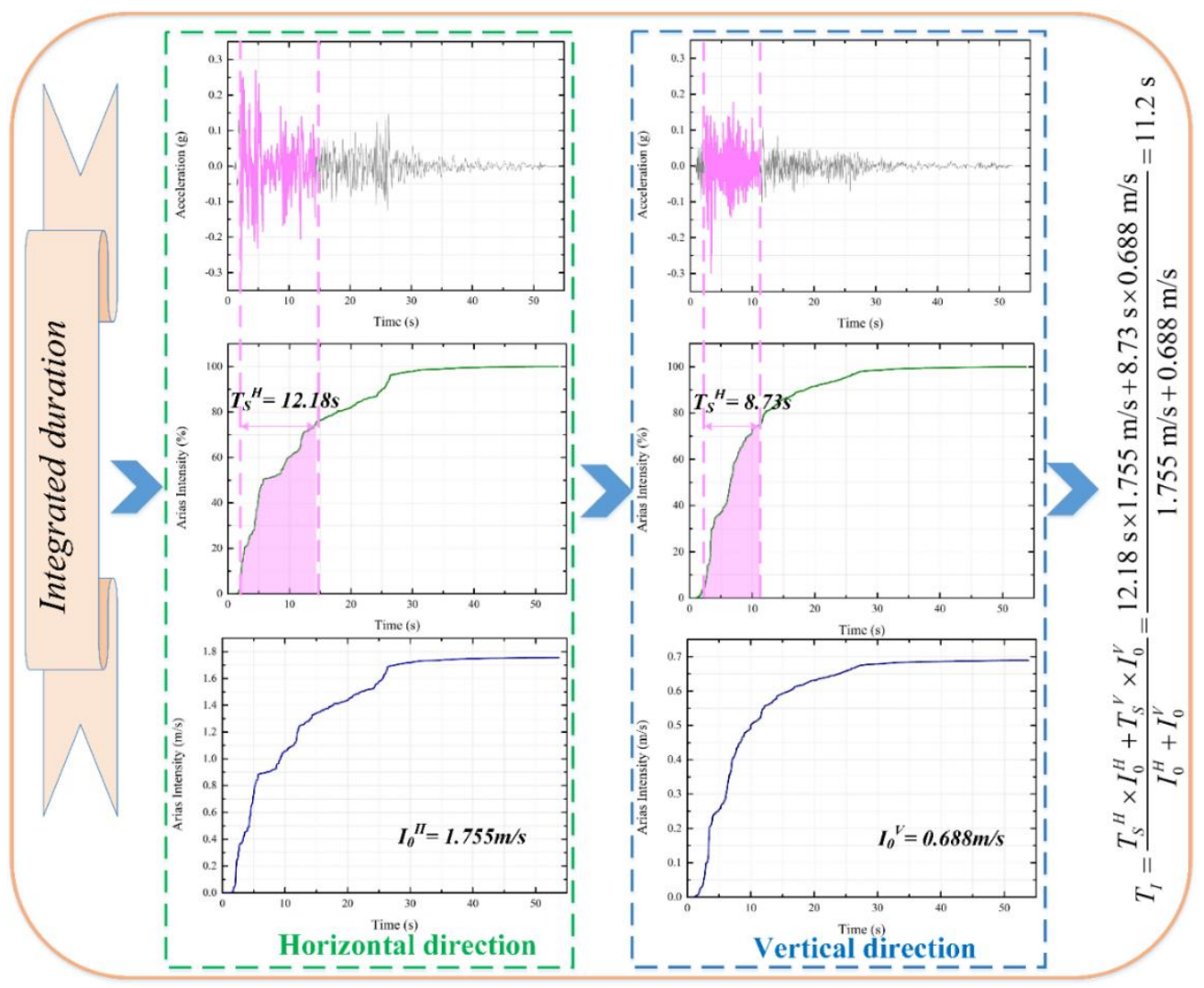


140 To reveal the seismic performance of ACCRDs considering the shorter duration and longer

141 duration effect, Forty - six bidirectional GMs are originated from the Pacific Earthquake Engineering

142 Research center (PEER) strong database. For each of these short - duration bidirectional GMs, a

143 corresponding long - duration bidirectional GMs with duration threshold longer than 25s (Barbosa et

144 al., 2017), and having original spectral acceleration and matching spectral acceleration is determined.

145 The detailed earthquake information is present in Table 1 and Table 2. On the other hand, it is crucial

146 to avoid the impact of frequency, amplitude and other characteristics of GMs on the seismic

147 performance assessment. All original GMs obtained PEER database are matched the target design

148 spectrum by using time domain wavelet correction method to adjust the amplitude and shape of

149 spectrum through the software of SeismoMatch. By doing so, the spectral acceleration of each

150 bidirectional earthquake records is adjusted and scaled to have a good compatible with the target

151 spectrum, reflecting that the influence of amplitude and shape of acceleration response spectrum can

152 be minimized, as shown in Fig. 5. Figure. 6 illustrates the distribution of GMDs of matched GMs.

153 Table 1

154 List of short - duration database with two directions (matched records).

\begin{tabular}{|c|c|c|c|c|c|c|c|c|c|c|}
\hline No. & Earthquake & Year & Station Name & Magnitude & Mechanism & Rrup (km) & Comp. & $\mathrm{SD}(5-75 \%)(\mathrm{s})$ & $\begin{array}{l}\text { Arias } \\
(\mathrm{m} / \mathrm{s})\end{array}$ & $\mathrm{ID}(\mathrm{s})$ \\
\hline \multirow[t]{2}{*}{1} & \multirow[t]{2}{*}{ Imperial Valley } & \multirow[t]{2}{*}{1940} & \multirow[t]{2}{*}{ El Centro Array \#9 } & \multirow[t]{2}{*}{6.95} & \multirow[t]{2}{*}{ strike slip } & \multirow[t]{2}{*}{6.09} & 180 & 20.35 & 0.35 & \multirow[t]{2}{*}{16.09} \\
\hline & & & & & & & up & 9.31 & 0.22 & \\
\hline \multirow{2}{*}{2} & \multirow{2}{*}{ Imperial Valley } & \multirow{2}{*}{1951} & \multirow{2}{*}{ El Centro Array \#9 } & \multirow[b]{2}{*}{5.6} & \multirow{2}{*}{ strike slip } & \multirow[b]{2}{*}{25.24} & 0 & 12.22 & 0.06 & \multirow{2}{*}{15.61} \\
\hline & & & & & & & up & 20.69 & 0.04 & \\
\hline \multirow{2}{*}{3} & \multirow{2}{*}{ Kern County } & \multirow{2}{*}{1952} & Pasadena - CIT & \multirow{2}{*}{7.36} & \multirow{2}{*}{ Reverse } & \multirow{2}{*}{125.59} & 180 & 15.86 & 0.08 & \multirow{2}{*}{17.77} \\
\hline & & & Athenaeum & & & & up & 20.32 & 0.06 & \\
\hline \multirow{2}{*}{4} & \multirow{2}{*}{ Imperial Valley } & \multirow{2}{*}{1953} & \multirow{2}{*}{ El Centro Array \#9 } & \multirow{2}{*}{5.5} & \multirow{2}{*}{ strike slip } & \multirow{2}{*}{15.64} & 0 & 6.4 & 0.03 & \multirow[t]{2}{*}{7.92} \\
\hline & & & & & & & up & 8.83 & 0.05 & \\
\hline
\end{tabular}




\begin{tabular}{|c|c|c|c|c|c|c|}
\hline 5 & Northern Calif & 1954 & Ferndale City Hall & 6.5 & strike slip & 27.02 \\
\hline 6 & Hollister-01 & 1961 & Hollister City Hall & 5.6 & strike slip & 19.56 \\
\hline 7 & Parkfield & 1966 & $\begin{array}{c}\text { Cholame - Shandon } \\
\text { Array } \# 12\end{array}$ & 6.19 & strike slip & 17.64 \\
\hline
\end{tabular}

$\begin{array}{lll}44 & 12.12 & 0.13 \\ \text { up } & 9.07 & 0.06 \\ 180 & 10.76 & 0.08\end{array}$

8 Borrego Mtn 1968 LA - Hollyw00d Stor FF 6.63

1968 LA - Hollywood Stor FF $6.63 \quad$ strike slip 222.42
San Onofre - So Cal

$9 \begin{array}{cccc} & \text { San Onofre - So Cal } & & \\ & \text { Borrego Mtn } & \text { Edrike slip } & \end{array}$

10 San Fernando 1971 Borrego Springs Fire Sta $6.61 \quad$ Reverse 214.32

214.32

11 San Fernando $1971 \quad$ Buena Vista - Taft $\quad 6.61 \quad$ Reverse 112

12 San Fernando $\quad 1971 \quad \begin{gathered}\text { Cedar Springs_Allen } \\ \text { Ranch } \\ 13\end{gathered}$

1

$14 \quad$ San Fernando 1971

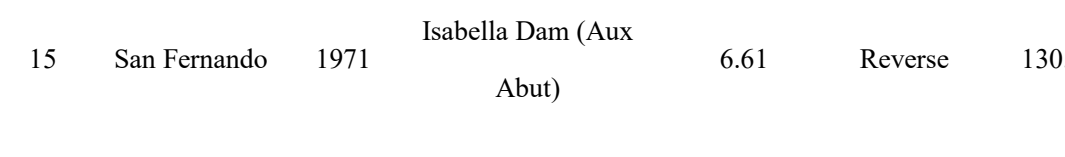

16 San Fernando 1971 LA - Hollywood Stor FF $6.61 \quad$ Reverse 22.77

17 San Fernando 1971 Maricopa Artay 22.77

17 San Fernando $1971 \quad$ Maricopa Array \#1 $6.61 \quad$ Reverse 193.91

\begin{tabular}{|c|c|c|c|c|c|c|c|c|c|}
\hline & 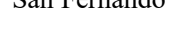 & & arcopa Amray & & The & & down & 12.02 & 0.05 \\
\hline & & & & & & & 130 & 14.29 & 0.05 \\
\hline 18 & San Fernando & 1971 & Maricopa Array \#2 & 6.61 & Reverse & 109.73 & down & 12335 & 004 \\
\hline
\end{tabular}

19 San Fernando $\quad 1971 \quad$ Maricopa Array \#3 $\quad 6.61 \quad$ Reverse $\quad 110.18 \quad \begin{array}{llll}130 & 10.21 & 0.04\end{array}$

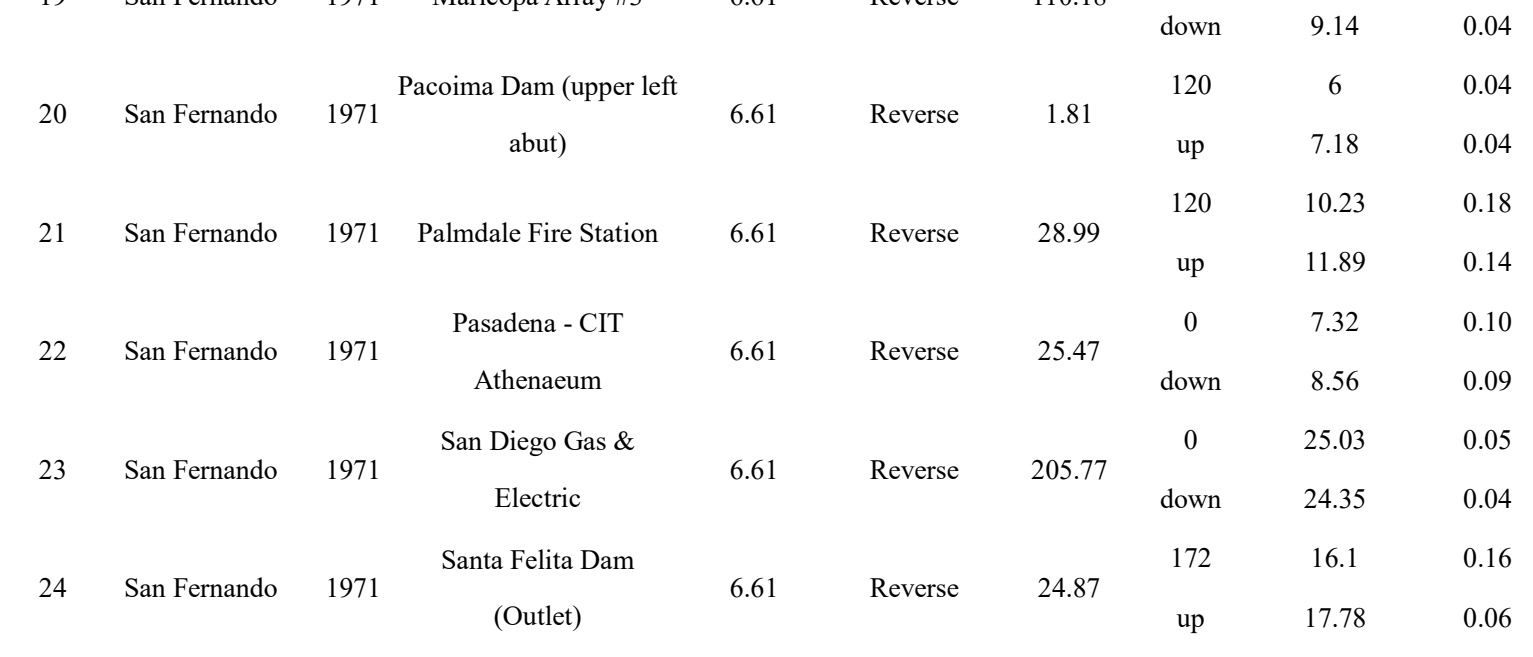

11.16

12.95

13.42 


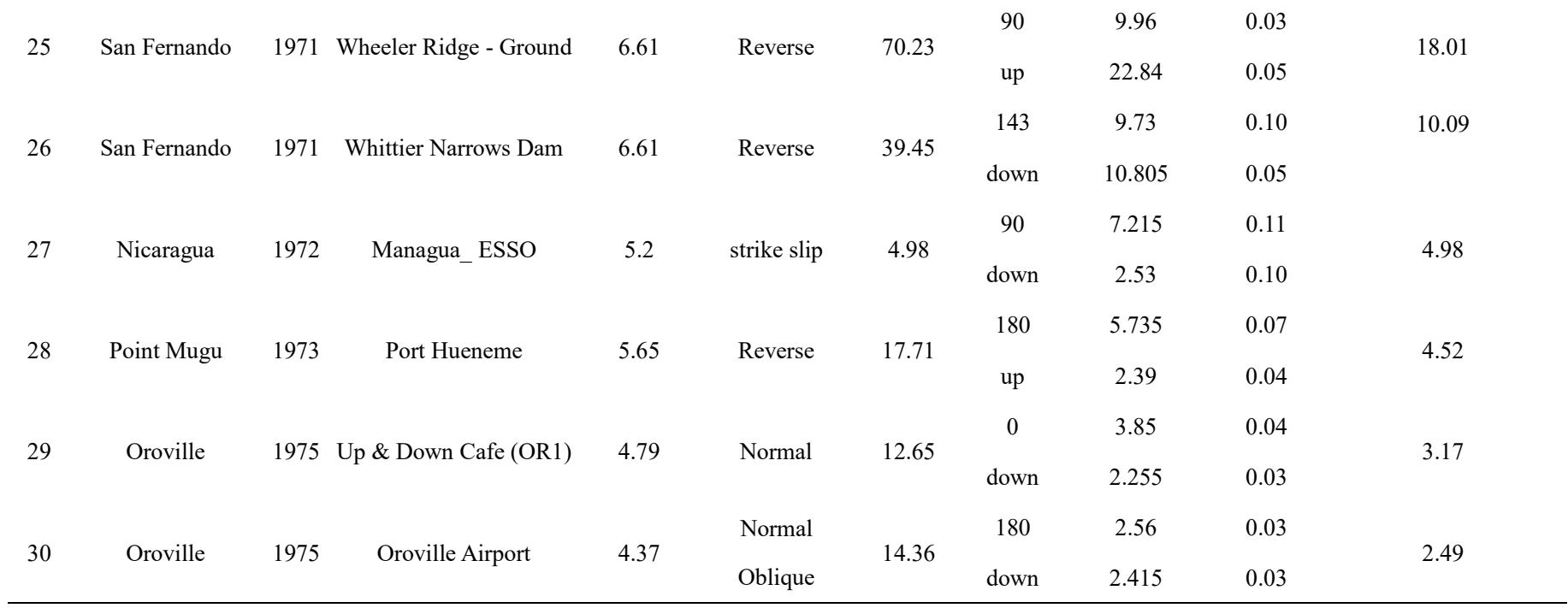

155 Table 2

156 List of long - duration database with two directions (matched records).

\begin{tabular}{|c|c|c|c|c|c|c|c|c|c|c|}
\hline No. & Earthquake & Year & Station & Magnitude & Mechanism & Rrup (km) & Comp. & $\begin{array}{c}\mathrm{SD}(5-75 \%) \\
(\mathrm{s})\end{array}$ & $\begin{array}{l}\text { Arias } \\
(\mathrm{m} / \mathrm{s})\end{array}$ & ID (s) \\
\hline 1 & Borrego Mtn & 1968 & $\begin{array}{c}\text { El Centro Array } \\
\# 9\end{array}$ & 6.63 & strike slip & 45.66 & $\begin{array}{l}180 \\
\text { up }\end{array}$ & $\begin{array}{c}25.54 \\
26.8\end{array}$ & $\begin{array}{l}0.24 \\
0.02\end{array}$ & 25.64 \\
\hline 2 & Morgan Hill & 1984 & $\begin{array}{c}\text { Fremont - Mission } \\
\text { San Jose }\end{array}$ & 6.19 & strike slip & 31.34 & $\begin{array}{l}75 \\
\text { up }\end{array}$ & $\begin{array}{l}23.18 \\
26.85\end{array}$ & $\begin{array}{l}0.33 \\
0.33\end{array}$ & 25.01 \\
\hline 3 & Landers & 1992 & $\begin{array}{c}\text { Mission Creek } \\
\text { Fault }\end{array}$ & 7.28 & strike slip & 26.96 & $\begin{array}{l}0 \\
\text { up }\end{array}$ & $\begin{array}{l}51.89 \\
50.46\end{array}$ & $\begin{array}{l}0.52 \\
0.54\end{array}$ & 51.16 \\
\hline 4 & Chi-Chi & 1999 & CHY076 & 7.62 & $\begin{array}{l}\text { Reverse } \\
\text { Oblique }\end{array}$ & 42.15 & $\begin{array}{l}\mathrm{E} \\
\mathrm{V}\end{array}$ & $\begin{array}{l}64.43 \\
46.12\end{array}$ & $\begin{array}{l}1.23 \\
1.57\end{array}$ & 54.16 \\
\hline 5 & Chi-Chi & 1999 & CHY082 & 7.62 & $\begin{array}{l}\text { Reverse } \\
\text { Oblique }\end{array}$ & 36.09 & $\begin{array}{l}\mathrm{E} \\
\mathrm{V}\end{array}$ & $\begin{array}{l}54.82 \\
42.24\end{array}$ & $\begin{array}{l}1.68 \\
0.51\end{array}$ & 51.89 \\
\hline 6 & Chi-Chi & 1999 & KAU001 & 7.62 & $\begin{array}{l}\text { Reverse } \\
\text { Oblique }\end{array}$ & 44.93 & $\begin{array}{l}\mathrm{N} \\
\mathrm{V}\end{array}$ & $\begin{array}{l}34.82 \\
58.74\end{array}$ & $\begin{array}{l}1.12 \\
0.63\end{array}$ & 43.44 \\
\hline 7 & Chi-Chi & 1999 & KAU077 & 7.62 & $\begin{array}{l}\text { Reverse } \\
\text { Oblique }\end{array}$ & 82.96 & $\begin{array}{l}\mathrm{E} \\
\mathrm{V}\end{array}$ & $\begin{array}{l}37.95 \\
32.09\end{array}$ & $\begin{array}{l}0.92 \\
1.08\end{array}$ & 34.79 \\
\hline 8 & Chuetsu-oki & 2007 & AKTH02 & 6.8 & Reverse & 285.32 & $\begin{array}{l}\text { NS } \\
\text { up }\end{array}$ & $\begin{array}{l}22.835 \\
46.325\end{array}$ & $\begin{array}{l}0.81 \\
1.33\end{array}$ & 37.43 \\
\hline 9 & Chuetsu-oki & 2007 & IWTH05 & 6.8 & Reverse & 271.78 & $\begin{array}{l}\text { NS } \\
\text { up }\end{array}$ & $\begin{array}{c}72.59 \\
102.83\end{array}$ & $\begin{array}{l}0.59 \\
0.97\end{array}$ & 91.39 \\
\hline 10 & Iwate & 2008 & FKS025 & 6.9 & Reverse & 188.17 & $\begin{array}{l}\text { NS } \\
\text { up }\end{array}$ & $\begin{array}{l}37.37 \\
44.52\end{array}$ & $\begin{array}{l}0.25 \\
0.47\end{array}$ & 42.04 \\
\hline 11 & Iwate & 2008 & FKSH05 & 6.9 & Reverse & 194.76 & $\begin{array}{l}\text { NS } \\
\text { up }\end{array}$ & $\begin{array}{c}43.3 \\
69.97\end{array}$ & $\begin{array}{l}0.41 \\
0.42\end{array}$ & 56.80 \\
\hline 12 & Tottori & 2000 & MIEH05 & 6.61 & strike slip & 275.84 & $\begin{array}{l}\text { NS } \\
\text { up }\end{array}$ & $\begin{array}{l}41.055 \\
45.75\end{array}$ & $\begin{array}{l}1.17 \\
0.17\end{array}$ & 41.65 \\
\hline 13 & Niigata & 2004 & IBR006 & 6.63 & Reverse & 171.21 & $\begin{array}{l}\text { NS } \\
\text { up }\end{array}$ & $\begin{array}{l}27.05 \\
34.15\end{array}$ & $\begin{array}{l}0.26 \\
0.17\end{array}$ & 29.85 \\
\hline
\end{tabular}




\begin{tabular}{|c|c|c|c|c|c|c|c|c|c|c|}
\hline 14 & Niigata & 2004 & MYGH11 & 6.63 & Reverse & 243.44 & $\begin{array}{l}\text { NS } \\
\text { up }\end{array}$ & $\begin{array}{l}29.72 \\
39.38\end{array}$ & $\begin{array}{l}0.46 \\
0.45\end{array}$ & 34.50 \\
\hline 15 & Niigata & 2004 & TYM003 & 6.63 & Reverse & 127.28 & $\begin{array}{l}\text { NS } \\
\text { up }\end{array}$ & $\begin{array}{l}24.07 \\
32.28\end{array}$ & $\begin{array}{l}0.25 \\
0.27\end{array}$ & 28.37 \\
\hline 16 & Darfield & 2010 & TRCS & 7 & strike slip & 95.85 & $\begin{array}{l}\text { E } \\
\text { up }\end{array}$ & $\begin{array}{c}20.955 \\
29.81\end{array}$ & $\begin{array}{l}0.60 \\
0.73\end{array}$ & 25.82 \\
\hline
\end{tabular}

157

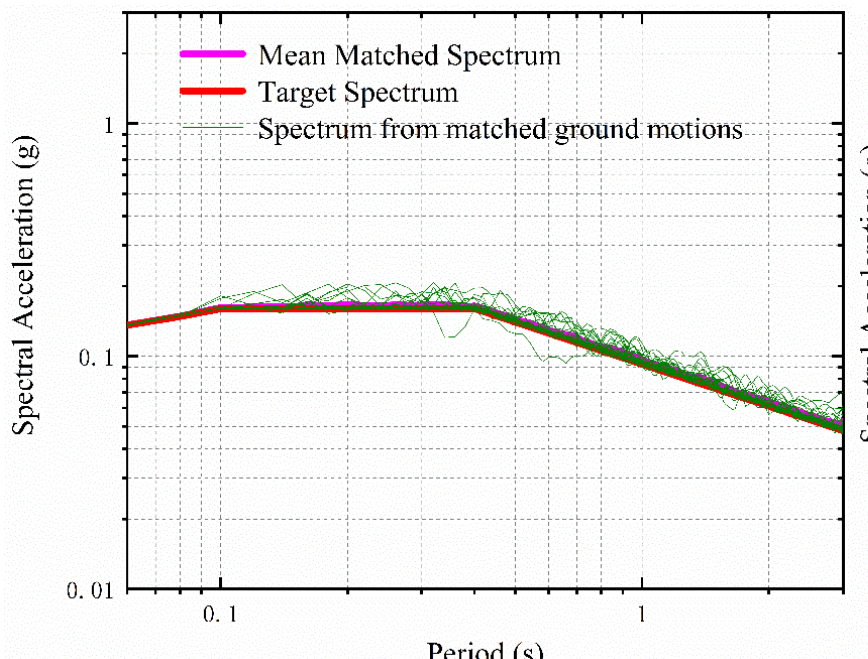

(a)

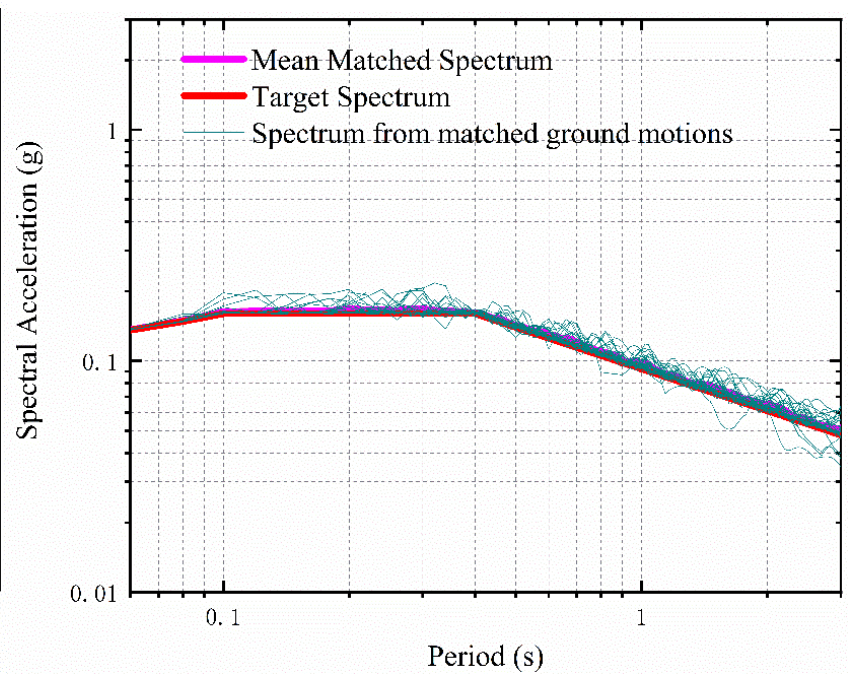

(b)

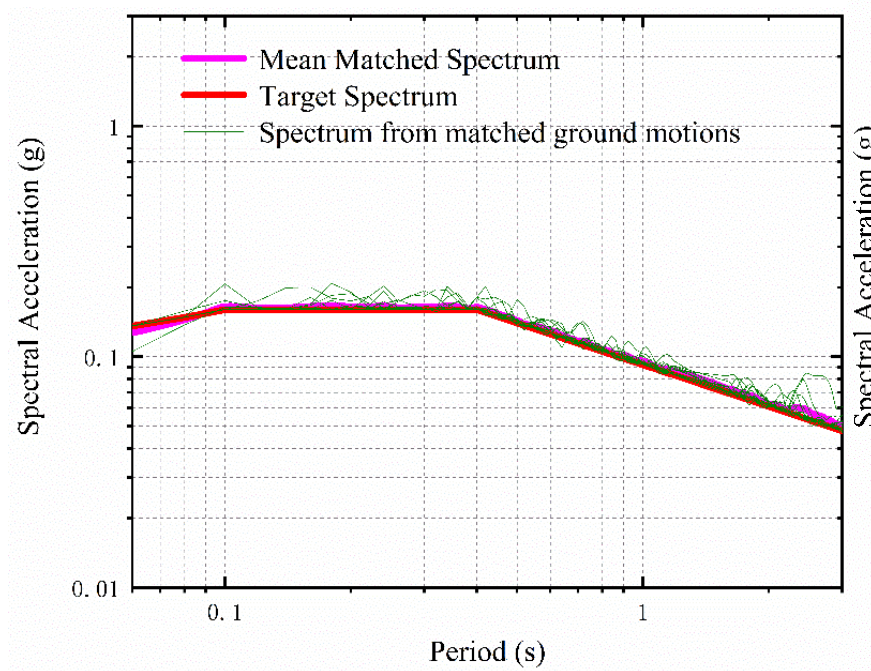

(c)

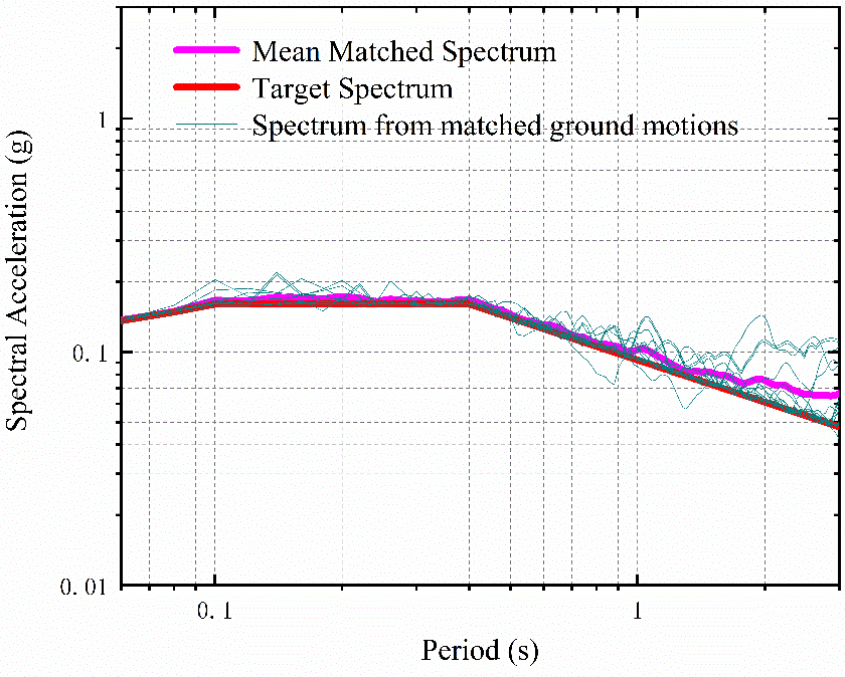

(d)

162 Fig. 4. Comparison of the adjusted response spectra of short - and long - duration GMs: (a) horizontal short - duration; (b)

163 vertical direction short - duration; (c) horizontal long - duration; (b) vertical direction long - duration. 


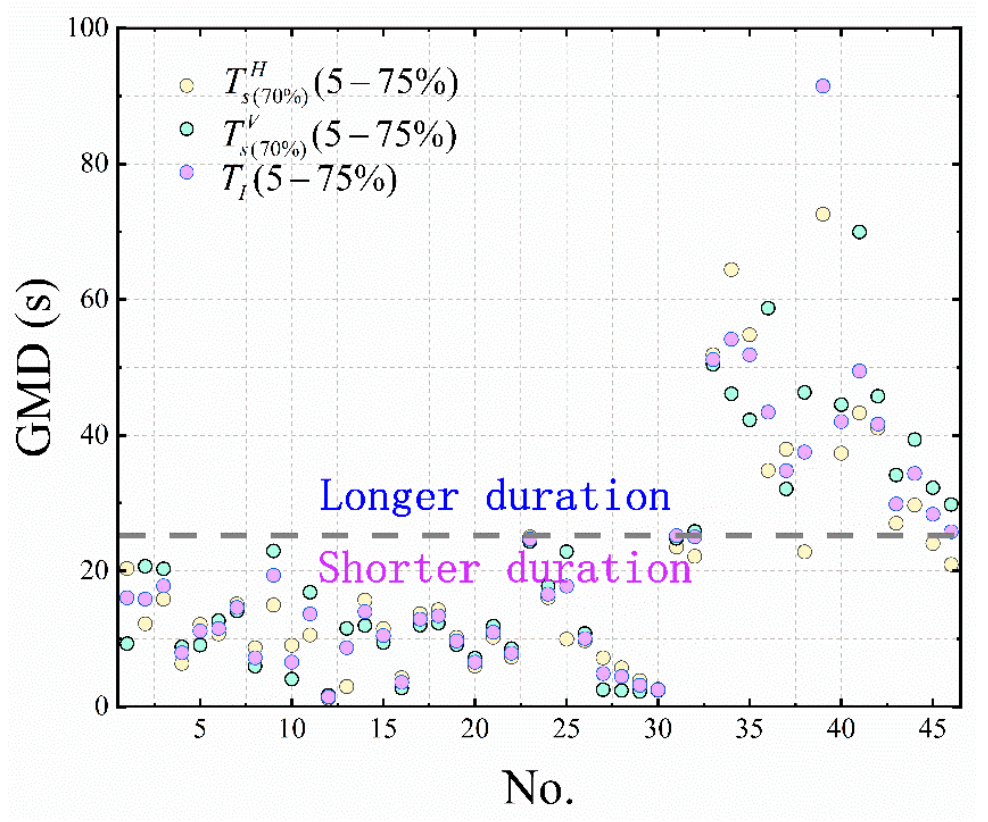

Fig. 5. Distribution of GMD in database after matching spectral acceleration.

\section{3. Framework for seismic performance assessment}

\subsection{Fragility function} The development of fragility curves of ACCRDs under short - and long - duration GMs are

169 significant steps for seismic performance assessment according to the performance-based earthquake

170 engineering (PBEE) framework. For the purpose of assessing the seismic performance of high dams,

171 there have been several in-depth approaches to collecting the results for generating fragility curves,

172 such as incremental dynamic analysis (IDA) (Vamvatsikos and Cornell, 2004), multiple stripe analysis

173 (MSA) (Baker, 2015), and cloud analysis (Celik and Ellingwood, 2010). IDA is an efficient

174 performance evaluation methodology, which linearly scaled from a low seismic intensity level to an

175 extremely high seismic intensity level for each selected GMs. MSA is conducted at a specified set of

176 seismic intensity level, each of which has engineering demand parameters (EDP). As the type of results 
177 collected in these two methods differs, the effectively approach for estimating fragility curves from

178 the results also differs. It is worth noting that the efficient fragility estimates of IDA may be lower than

179 MSA for a given number of high performance structures. In this study, the fragility curves for the

180 ACCRD are investigated employing the MSA approach. Besides, the PGA of GMs is acknowledged

181 as the variable on behalf of the intensity measure (IM) of short - and long - duration GMs, and is

182 scaled from $0.1 \mathrm{~g}$ to $0.7 \mathrm{~g}$ in gaps of $0.1 \mathrm{~g}$.

183 As a critical and integrated component of a PBEE framework (Fajfar, 2000), the mainly purpose

184 of FR is to quantify the probability of exceedance (POE) relationships between structural damage state

185 with the various IM level. The fragility curves of an ACCRD can be conducted by a lognormal 186 cumulative distribution function (Baker, 2015):

$$
F R(x)=\Phi\left(\frac{\operatorname{In}(x / \theta)}{\beta}\right)
$$

where $F R(x)$ is the POE that the structural damage state under a particularly seismic intensity level reaching the specific DS; $\theta$ and $\beta$ are the median and the logarithmic standard deviation of the

190 fragility function (the seismic intensity level with 50\% POE) that is connected with the EDP and 191 structural capacity (Baker, 2015), respectively; $\Phi$ is the fragility curves function that belong to the 192 normal cumulative distribution. It is worth noting that the generally lognormal distribution is not only 193 one methodology that can be applied on Eq. (4). In this study, the methodology of MSA and maximum 194 likelihood estimate (MLE) is employed to fit the fragility curves.

On the basis of MSA-MLE, an analytical estimation approach is depicted in the present study to 196 generate the FR. At different seismic intensity level $I M=x_{i}$, the time - history analyses conduct 
on the sensitive extent of seismic behavior of structures under different GMD are obviously mixed results. GMs. Assuming that collection of EDPs from short - and long - duration GMs are 200 independent of collections from other GMs, the probability of observing $n_{i}$ collapses out of $n_{j}$ 201 GMs with $I M=x_{j}$ is given by the binomial distribution:

$$
P\left(n_{i} \text { collapses in } N_{i} \text { short and long ground motions } \mid I M=I M_{i}\right)=\left(\begin{array}{c}
N_{i} \\
n_{i}
\end{array}\right) p_{i}^{n_{i}}\left(1-p_{j}\right)^{N_{i}-n_{i}}
$$

203 where $p_{i}$ is the probability of collapse of the structure under short - and long - duration GMs with $204 I M=I M_{i}$

Following the MLE approach, the way to identify the fragility function for $p_{i}$ is to select the 206 function that gives us the highest probability of observing the collapse data that was originated from 207 nonlinear dynamic analysis. Subsequently, the product of binominal probabilities according to Eq. (5) 208 at each IM levels, is employed to get the likelihood in the entire database.

$$
\text { Likelihood }=\prod_{i=1}^{m} P\left(n_{i} \text { collapses in } N_{i} \text { short and long ground motions } \mid I M=I M_{i}\right)=\prod_{i=1}^{m}\left(\begin{array}{c}
N_{i} \\
n_{i}
\end{array}\right) p_{i}^{n_{i}}\left(1-p_{i}\right)^{N_{i}-n_{i}}
$$

211 where $m$ is the number of short - and long - duration GMs at each IM levels; $\prod$ represent a 212 product over all dates.

213 To conduct this maximize the likelihood function, $p_{i}$ is replaced by the Eq. (4), and estimation

214 of the key parameters $\hat{\theta}$ and $\hat{\beta}$ (logarithmic mean and standard deviation) are then obtained by this

215 likelihood function. It is worth noting that the estimation of parameters by maximizing the logarithm

216 of the likelihood, which is equivalent and numerically more efficient and easier than the maximizing 217 the likelihood function itself, so that the fragility function can be explicit as follows: 


$$
\hat{\theta}, \hat{\beta}=\arg \max _{\theta, \beta} \sum_{i=1}^{m}\left[\ln \left(\begin{array}{c}
N_{i} \\
n_{i}
\end{array}\right) n_{i} \ln \left(\Phi\left(\frac{\ln \left(x_{i}\right)-\theta}{\beta}\right)\right)+\left(N_{i}-n_{i}\right) \ln \left(1-\Phi\left(\frac{\ln \left(x_{i}\right)-\theta}{\beta}\right)\right)\right]
$$

Standard commercial software packages such as Matlab, R, python, or Microsoft Excel can be

utilized to calculate the Eq. (7), and detailed code can be found in the work of Baker (Baker, 2015).

\subsection{Definitions of seismic performance indicators}

After the earthquake disaster, the potential failure mode (PFM) of high dams is generally depicted

as a function of concrete stiffness degradation, concrete strength degradation, dam crest settlement,

224 landslide, cracks and liquidation among others. Due to the complex combination of these PFMs, the

225 unsatisfactory performance and uncontrolled failure mode of high dams can be regarded as a chain of

events. In addition, high ACCRDs are the complex system mainly composed of rockfill, transition and

high ACCRDs under shorter duration and longer duration GMs.

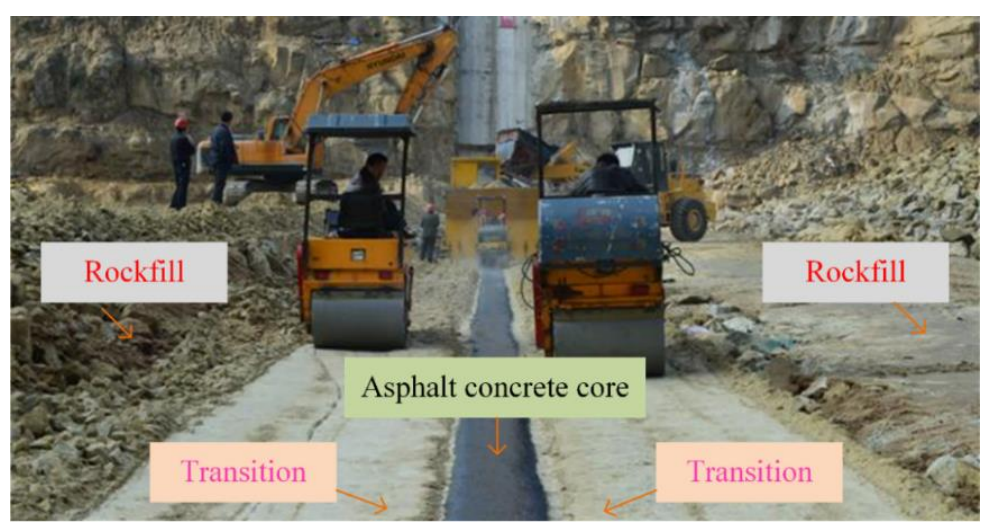

Fig. 6. Construction of high ACCRD.

The relative settlement ratio (RSR) of dam crest is one of the most generally seismic damage 
modes of embankment dams. Swaisgood (2003) surveyed 69 embankment dams settlement and deformation, including concrete faced rockfill dams, earth core rockfill dams, earthfill dams, hydraulic

237 fill dams, and recommended RSR of dam crest as an seismic performance index. Besides, the seismic 238 performance index is divided the PFM situation into four performance levels: none $(<0.1 \%)$, minor $239(0.012-0.5 \%)$, moderate $(0.1-1.0 \%)$ and severe $(>1 \%)$, as displayed in Fig. 7. Based on the work 240 of Swaisgood et al. (2003), Wang et al. (2015) proposed the RSR of $0.1 \%, 0.4 \%$ and $1 \%$ as the assessment performance levels when this embankment dams reached to minor, moderate and severe.

242 To more safely assess the seismic performance of the high ACCRD, the four performance levels of 243 embankment dam proposed by Wang et al. (2015) is utilized in this paper.

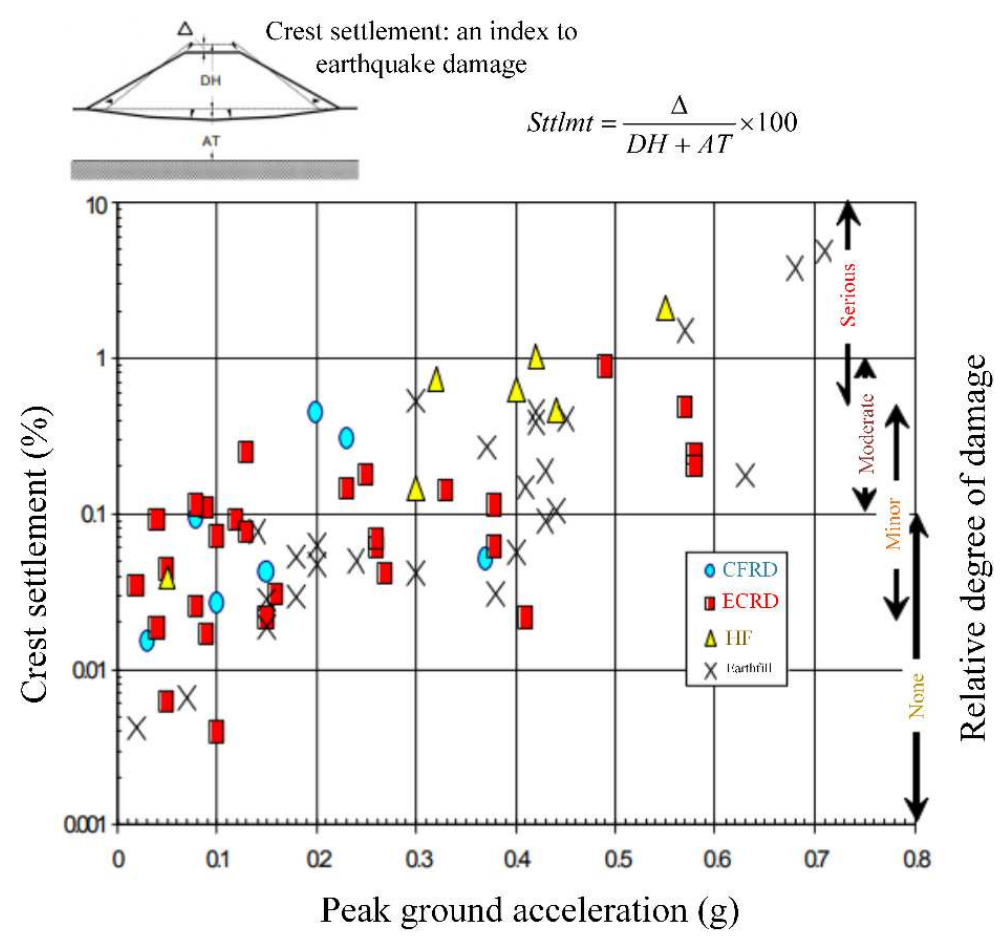

Fig. 7. Construction of high ACCRD.

The seismic performance of the asphalt concrete core, employed as an indispensable component 
249 materials structure is firstly proposed by Ghanaat (2004). Subsequently, the performance index is 250 widely employed to forecast the seismic performance of concrete gravity dams (Wang et al., 2014), 251 concrete arch dams (Ardebili and Mirzabozorg, 2012) and concrete face rockfill dams (Xu et al., 2020).

252 As shown in Fig. 8, the performance index is systematic and rational formulated in light of the stress 253 demand-capacity ratios (DCR), the cumulative inelastic duration (CID), overstressed regions of 254 concrete materials, and other considerations form the basis for an approximate and qualitative estimate 255 of damage. The DCR can be calculated according to the follow formula:

$$
D C R=\frac{\sigma_{d}}{f_{t}}
$$

257 where $\sigma_{d}$ is the maximum tensile stress during dynamic analysis; $f_{t}$ is ultimate tensile stress 258 strength of concrete materials.

259 The static tensile strength of concrete materials characterized by the standard un-axial splitting 260 tension experimental tests or from:

$$
f_{t}=1.7 f_{c}^{\prime 2 / 3}
$$

262 where $f_{c}$ represent the static ultimate compressive strength of concrete materials. The maximum 263 permitted DCR of dams is 2 during the dynamic analysis, which means the maximum tensile stress 264 twice the ultimate tensile stress strength of the concrete materials. In this study, the experimental 265 compressive strength of the asphalt concrete is approximately $1.6 \mathrm{MPa}$ under $10^{\circ}$ condition (Feng et 266 al., 2020; Ning et al., 2020, 2019), and the corresponding tensile strength of asphalt concrete can be 267 obtained from the Eq. (9).

The CID refers to the total duration of cyclic stress above a certain stress strength, which is related to different DCR levels. As shown in Fig. 8(a), the hypothetical harmonic stress time - history 
270 (oscillation period of 0.24 s) includes 5 cyclic tensile stress (shaded area) exceeding the specific tensile

271 strength. Between one oscillation period, the CID of the stress excursion beyond the upper tensile

272 strength (shaded area) is taken equal to $0.8 \mathrm{~s}(T / 3)$. The total cumulative inelastic duration $(D C R \geq 1)$

273 for all 5 cycles exceeding the tensile strength amounts to $0.4 \mathrm{~s}$. Moreover, it can also be found from

274 Fig. 8(a) that the CID for a $D C R=2$ is assumed 0. Based on the high dams resist loads mechanism,

275 the cumulative duration of $0.3 \mathrm{~s}, 0.4 \mathrm{~s}$ and $0.6 \mathrm{~s}$ is respectively for gravity dams (Wang et al., 2014), arch

276 dams (Ardebili and Mirzabozorg, 2012) and concrete face rockfill dams (Pang et al., 2018; Xu et al.,

277 2020). In view of the fact that the recovery capacity of asphalt concrete and the resist loads mechanism

278 of asphalt concrete core is similar to gravity dams (cantilever mechanism), the CID is taken as 0.35 in

279 this paper. On the hand, the seismic performance of high ACCRDs is evaluated on the basis of the

280 combined criteria and their possible coupling (DCR-CID). Three performance levels are considered

281 according to the aforementioned assessment methodology:

282 1. Minor or no damage. The tensile stress of asphalt concrete core response is lower than extremely

283 tensile strength of asphalt concrete, which means the asphalt concrete core is in a no or minor damage

284 if $D C R \leq 1$.

285 2. Moderate damage. The asphalt concrete core will exhibit inelastic behavior in the form of damage

286 cracking if the estimated $D C R>1$. If the estimated $1<D C R<2,0<C I D \leq 3.5$ for all DCR's, and

287 overstressed regions are less than $15 \%$ of the asphalt concrete core, it is considered that the asphalt

288 concrete core is acceptable with no possibility of failure, as shown in Fig. 9

289 3. Severe Damage. The damage state of the asphalt concrete core is regarded as severe when $D C R>2$,

290 or $3.5<C I D$ for all DCR's given in Fig. 9. 
(a)
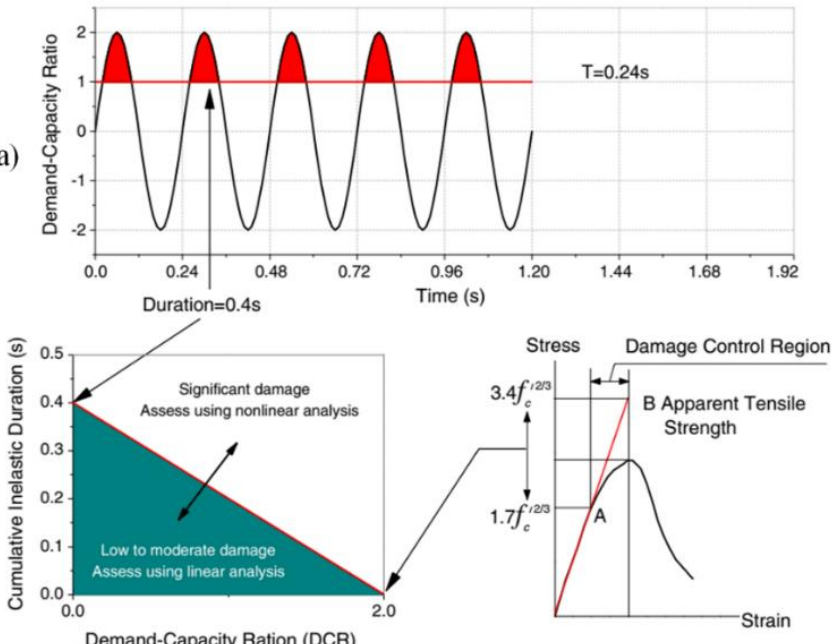

(b)

(c)

Fig. 8. Illustration of seismic performance and damage criteria (Ghanaat, 2004).

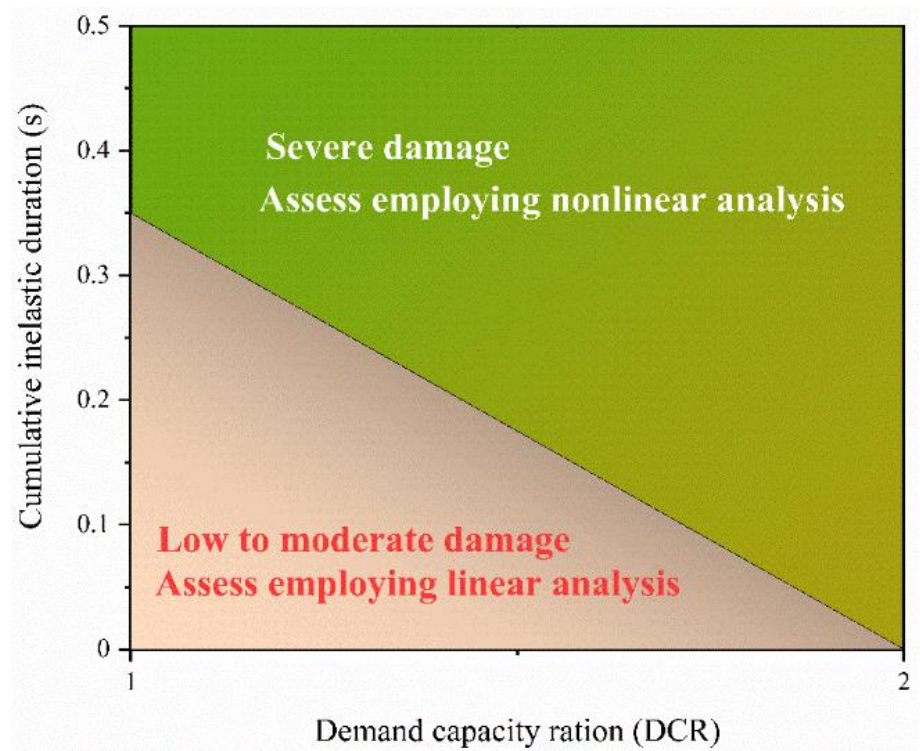

Fig. 9. Seismic performance and limit state threshold value of asphalt concrete core.

\section{4. Numerical case study}

\subsection{Engineering background of the Dashimen dam}

Dashimen dam is located on the Cheerchen River in Bayingol mongolian autonomous prefecture

298 (Xinjiang, China) and started construction in January 2018. It is planned to achieve the goal of 
299 impounding water for Dashimen dam in October 2020. Dashimen dam is currently the highest asphalt

300 concrete core rockfill dam in Xinjiang, with a maximum crest height of $130 \mathrm{~m}$, a crest length of 205

$301 \mathrm{~m}$, and a crest width of $12 \mathrm{~m}$ (see Fig. 10). The asphalt concrete core adopts the geometric form of

302 upper narrow and lower width. As shown on the Fig. 10, the top width and the bottom width of asphalt

303 concrete core is $0.6 \mathrm{~m}$ and $1.4 \mathrm{~m}$, respectively. In addition, there is a magnifying foot with a height of

$3043.2 \mathrm{~m}$, and the thickness of the magnifying foot changes gradually from $1.4 \mathrm{~m}$ to $2.6 \mathrm{~m}$. The total

305 storage capacity of the reservoir is 127 million cubic meters, and the adjusted storage capacity is 99

306 million cubic meters. The bedrock materials are composed of diabase, Jurassic mudstone, sandstone

307 and sand pebble bed. On the other hand, Dashimen dam is located in the regions where strong

308 earthquakes frequently occur with design peak ground acceleration (PGA), $P G A=0.52 g$. Seismic

309 performance of Dashimen dam under different seismic intensities GMs is a crucial factor for the

310 hydraulic engineering.

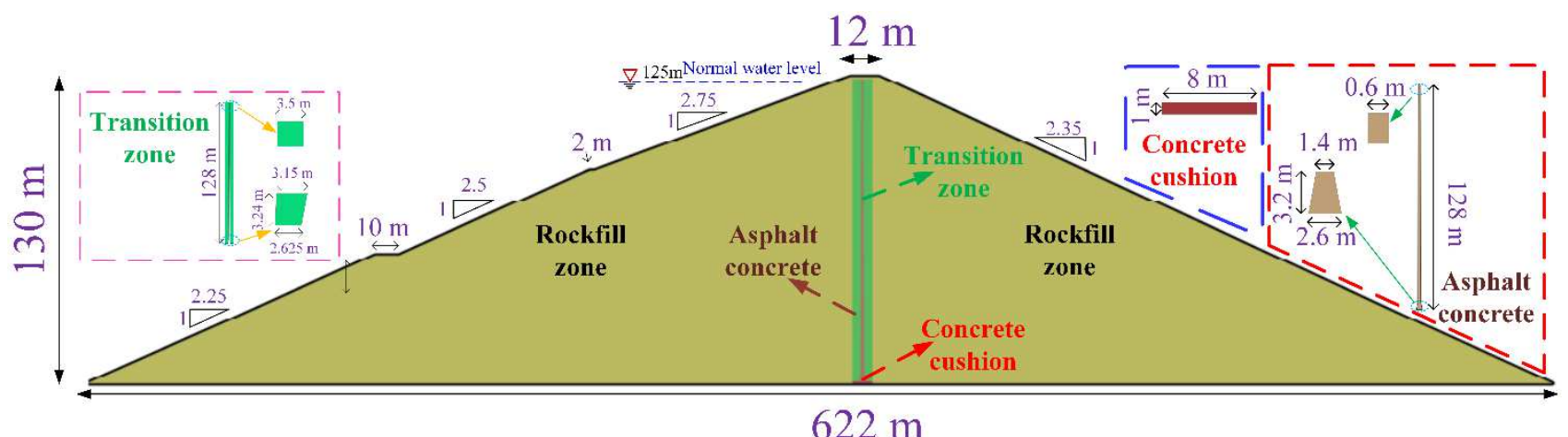

Fig. 10. Construction and design of Dashimen dam: (a) aerial view; (b) cross section

\section{4.2. Finite element model considering the dam - water - foundation interaction system}

dam - reservoir - foundation (DRF) interaction system is discretized into an assemblage of solid 
316 element, as decipted in Fig. 11. In these models, rockfill zone, transition zone, asphalt concrete core,

317 concrete cushion, foundation rock and reservoir water have 41742, 4032, 1344, 108, 132840 and 51318

318 finite elements, respectively. Moreover, 672 interface elements were defined in asphalt concrete core

319 - transition zone interface. The total numbers of integration points of the Dashimen dam body,

320 foundation rock and reservoir water are 57232, 157990 and 61138, respectively. To more precisely

321 simulate the seismic behaviour of the asphalt concrete core, four layers of spatial 8-node isoparametric

322 elements is employed to model the core thickness.

323 Before the time-history dynamic analyses, the initial stress condition for Dashimen dam needs to

324 be determined by static analysis. As shown in Fig. 11, the Dashimen dam reproducing a staged

325 construction and staged water impounding are step - by - step and are modelled with 11 steps and 12

326 steps, respectively. To reflect the extremely unfavorable water table of Dashimen dam, the presence of

327 water in the reservoir is assumed the case of full reservoir, which is impounded from dam base to dam

328 crest after dam construction was completed. Moreover, the water pressure is applied on the upstream

329 face of asphalt concrete core and concrete cushion by means of a triangular hydrostatic profile. The

330 static boundary conditions are restrained in the $\mathrm{x}, \mathrm{y}$ and $\mathrm{z}$ directions at the bottom truncated boundary.

331 For left and right boundaries, the static boundary conditions are fixed only in the lateral direction and

332 are free in the y direction. On the other hand, the front and back static boundary conditions of dam and

333 foundation rock are restrained in the $\mathrm{z}$ direction. During the filling and impounding process, the typical

334 hyperbolic Duncan Chang E-B model (Duncan and Chang, 1970) is used to describe the pre-seismic 335 stress-strain for rockfill zone, transition zone and asphalt concrete core. The detailed material 336 parameters of the Duncan E-B model are described in Table 3. 


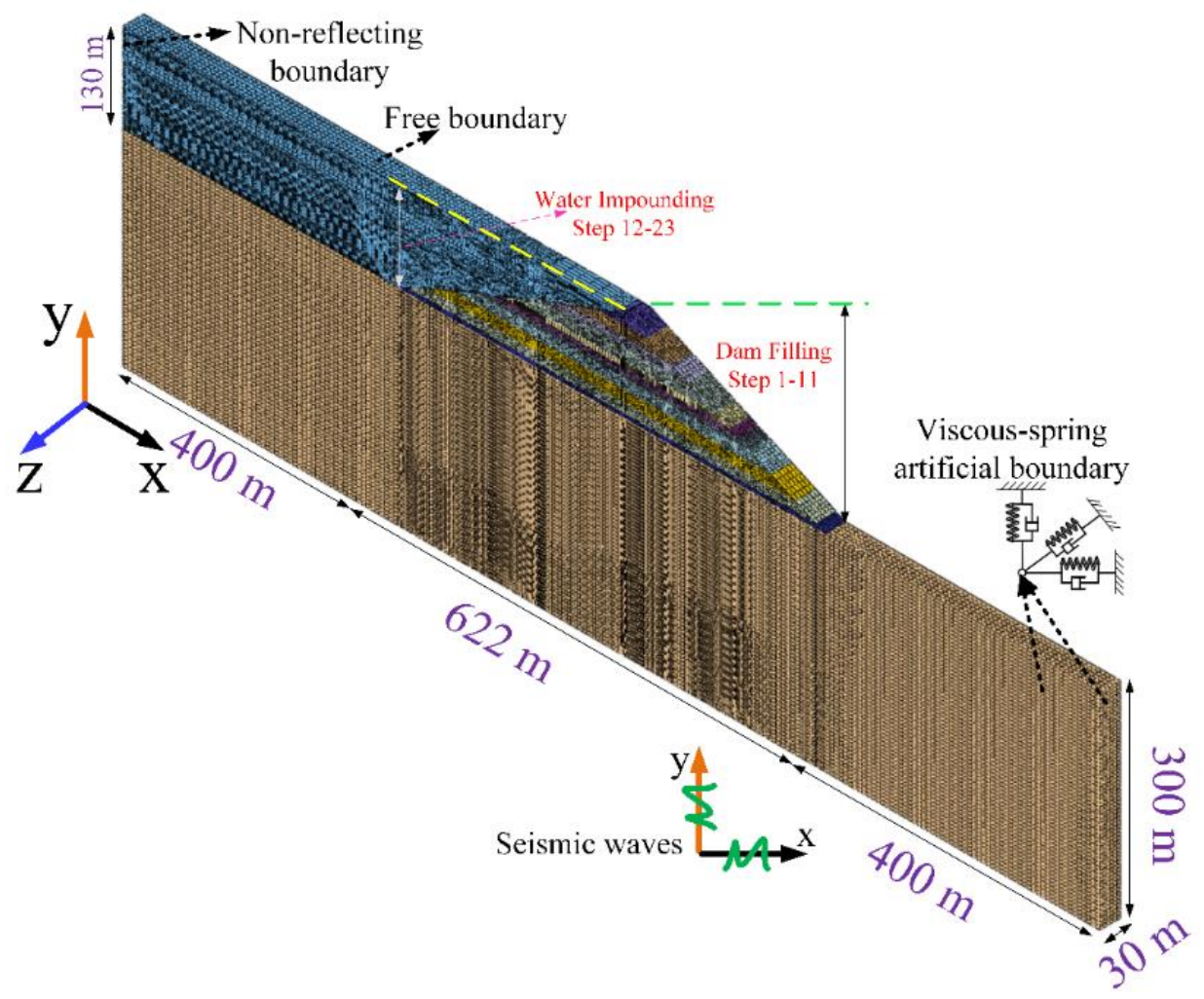

(a)

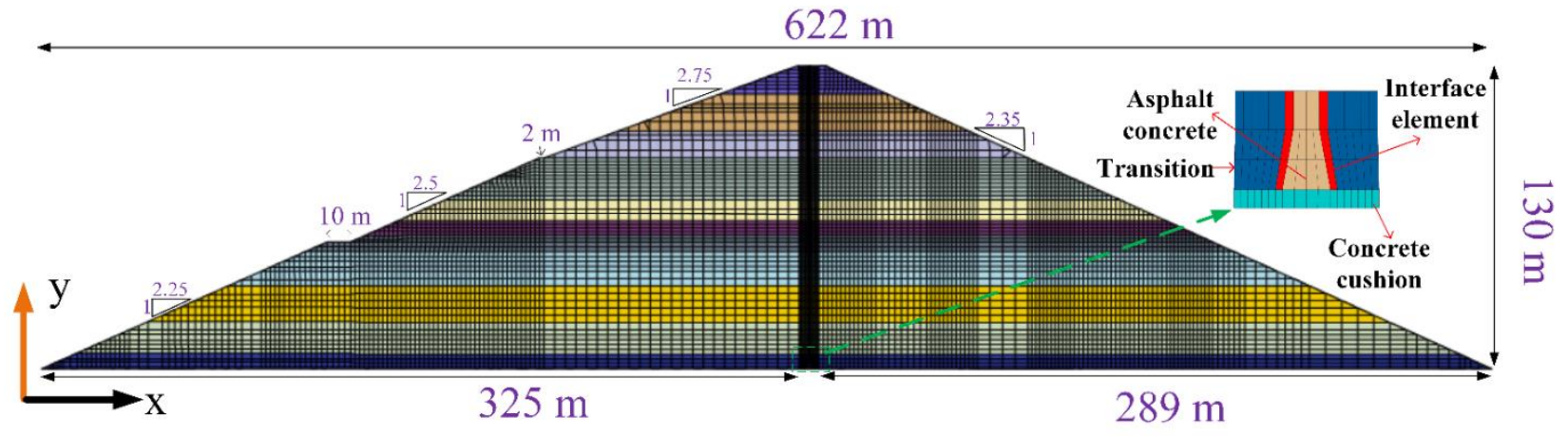

Fig. 11. Details of the high ACCRD - water - foundation FE model.

342 Table 3 Material parameters for Duncan E-B model (Kong et al., 2014; Li et al., 2020)

\begin{tabular}{ccccccccc}
\hline Materials & $\rho /\left(\mathrm{kg} / \mathrm{m}^{3}\right)$ & $K$ & $n$ & $R_{f}$ & $K_{b}$ & $m$ & $\varphi_{0} /(\mathrm{o})$ & $\Delta \varphi_{0} /(\mathrm{o})$ \\
\hline Rockfill & 2150 & 750 & 0.6 & 0.78 & 450 & 0.05 & 36 & 7.5 \\
Transion & 2200 & 1000 & 0.55 & 0.8 & 700 & 0.1 & 42 & 6.5 \\
Asphalt concrete & 2420 & 429.1 & 0.603 & 0.88 & 944 & 0.495 & 25.4 & 0 \\
\hline
\end{tabular}

In dynamic analyses of embankment dam, the equivalent linear viscoelasticity model (Hardin and 
344 Drnevich, 1972) have been widely used in practical engineering to reflect the mechanical seismic

345 behavior of rockfill zone, transition zone and asphalt concrete core $\left(10^{\circ}\right)$. Moreover, the model of 346 parameters are easily obtained from the experiment test. According to Hardin and Drnevich's 347 postulation which indicates that the maximum dynamic shear modulus of a damming rockfill and 348 asphalt concrete is formulated as follows (Hardin and Drnevich, 1972):

$$
G_{\max }=K \cdot p_{a} \cdot\left(p / p_{a}\right)^{n}
$$

350 where $K$ and $n$ is the experimental parameters, respectively; $p_{a}$ represent the standard 351 atmospheric pressure; $p$ is the average effective stress. The detailed model parameters are listed in 352 Table 4.

Table 4 Parameters for Hardin - Drnevich model (Kong et al., 2014; Li et al., 2020)

\begin{tabular}{cccc}
\hline Materials & $K$ & $n$ & $v$ \\
\hline Rockfill & 2270 & 0.273 & 0.22 \\
Transion & 2700 & 0.375 & 0.22 \\
Asphalt concrete $\left(10^{\circ}\right)$ & 1979 & 0.4 & 0.345 \\
\hline
\end{tabular}

The cycle earthquake load will induce the high ACCRDs to generate irrevocably permanent

355 deformation. However, the equivalent linear viscoelasticity model is only used to obtain the time

356 history curves of the shear strain, stress and acceleration, whereas the methodology cannot directly

357 obtain the permanent deformation of the dam body. Currently, there are many acceptably numerical

358 models according to the equivalent nodal force approach that are utilized to compute the permanent

359 deformation, such as the Serff and Seed model, the IWHR model, Taniguchi model, improved

360 Taniguchi model, Shen Zhu-jiang model and improved Shen Zhu-jiang model. The permanent

361 deformation of dam body is calculated according the work of Serff and Seed model (Serff et al., 1976).

362 Moreover, the relationships based on dynamic triaxial experiments and Shen Zhu-jiang model (Zhu- 
363 Jiang and Gang, 1996) of drainage conditions among the residual dynamic volumetric strain increment

$364 \Delta \varepsilon_{v r}$, the residual dynamic shear strain increment $\Delta \gamma_{r}$, the dynamic stress state and the vibration 365 duration can be expressed as follows (Zhu-Jiang and Gang, 1996):

$$
\Delta \varepsilon_{v r}=c_{1} \gamma_{d}^{c_{2}} \exp \left(-c_{3} S_{1}^{2}\right) \frac{\Delta N}{1+N}
$$

$$
\Delta \gamma_{r}=c_{4} \gamma_{c}^{c_{5}} S_{1}^{n} \frac{\Delta N}{1+N}
$$

where $c_{1}, c_{2}, c_{3}, c_{4}$, and $c_{5}$ are the experimental test parameters; $\gamma_{d}$ represents the dynamic

strain amplitude; $\Delta N$ and $N$ is the time increment and total vibration times, respectively; $S_{1}^{n}$ is the

stress level; $n$ is the stress level index and is generally $0.9-1.0$. The detailed permanent deformation

model parameters of the rockfill materials are shown in Table 5.

Table 5 Parameters for permanent deformation (Li et al., 2020)

\begin{tabular}{cccccc}
\hline Materials & $c_{1} /(\%)$ & $c_{2}$ & $c_{3}$ & $c_{4} /(\%)$ & $c_{5}$ \\
\hline Rockfill & 0.72 & 0.96 & 0 & 9.34 & 0.37 \\
Transion & 0.56 & 0.42 & 0 & 8.25 & 0.4 \\
\hline
\end{tabular}

For the concrete cushion, the mechanical responses and dynamic cracking mechanism is

374 specifically described by the concrete damage plastic (CDP) model in the ABAQUS material library.

375 The CDP model is firstly proposed by Lubliner et al. (1989) and improved by Lee and Fenves (1998).

376 Many previous studies demonstrate that the CDP model can particularly for simulating the realistic

377 dynamic crack profiles in concrete materials (Huang et al., 2017; B. Sun et al., 2020; Benbo Sun et al., 378 2020b; Wang et al., 2019). The foundation rock of Dashimen dam is assumed to be linearly elastic 379 model. Table 6 present the detailed material parameters of foundation rock and concrete cushion.

380 Table 6 Material parameters of bedrock and concrete cushion.

\begin{tabular}{cccc}
\hline Material & $\begin{array}{c}\text { Constitutive } \\
\text { model }\end{array}$ & Input parameter & Value \\
\hline (a) foundation rock & Linear elastic & Mass density & 2730 \\
\hline
\end{tabular}




\begin{tabular}{|c|c|c|c|}
\hline \multirow{9}{*}{ (b) Concrete cushion } & & $\mathrm{P}\left(\mathrm{kg} / \mathrm{m}^{3}\right)$ & \\
\hline & & Elastic modulus (GPa) & 5.0 \\
\hline & & Poisson's ratio & 0.25 \\
\hline & $\begin{array}{c}\text { Concrete } \\
\text { damage plastic } \\
\text { model }\end{array}$ & $\begin{array}{c}\text { Mass density } \\
\rho\left(\mathrm{kg} / \mathrm{m}^{3}\right)\end{array}$ & 2450 \\
\hline & & Elastic modulus (GPa) & 28 \\
\hline & & Poisson's ratio & 0.167 \\
\hline & & Tensile yield stress (MPa) & 1.78 \\
\hline & & Compressive yield stress (MPa) & 16.7 \\
\hline & & Dynamic magnification factor & 1.2 \\
\hline
\end{tabular}

Generally, to obtain more accurate numerical results, the contact element should be defined to

382 reflecting the interface behavior between two materials with significantly different mechanical

383 property. In this paper, the Goodman zero-thickness contact element is used to simulate the transition

$384-$ concrete interface. Moreover, the thin-layer contact element $(5 \mathrm{~cm})$ is applied between transition and

385 asphalt concrete to revel the contact behavior. Although many models have been proposed to reflect

386 the strain - stress relationship of contact element, a Clough - Duncan hyperbolic model is employed

387 for the contact element and the parameters of hyperbolic model can be easily obtained from shear test

388 experiment. The dynamic hyperbolic model developed by Wu et al. (1992) is applied to simulate the

389 dynamic behavior of the contact element. The detailed parameters of the contact element are presented 390 in Tables 7 and 8.

Table 7 Parameters for static contact element (Ji, 2006)

\begin{tabular}{cccccc}
\hline Contact element & Materials & $K$ & $n$ & $\varphi$ & $R_{f}$ \\
\hline Thin-layer contact element & Transition - asphalt concrete & 3200 & 0.42 & 27 & 0.65 \\
Goodman zero-thickness contact element & Transition-concrete cushion & 5600 & 0.52 & 36 & 0.86 \\
\hline
\end{tabular}

Table 8 Parameters for dynamic contact element (Ji et al., 1995; Wu et al., 1992)

\begin{tabular}{cccccc}
\hline Contact element & Materials & $C$ & $M$ & $\delta$ & $\lambda \max$ \\
\hline Thin-layer contact element & Transition - asphalt concrete & 300 & 0.96 & 0.58 & 0.15 \\
Goodman zero-thickness contact element & Transition-concrete cushion & 22 & 2.0 & 34 & 0.2 \\
\hline
\end{tabular}

For embankment dams, hydrodynamic pressure generally has no significantly effect on the dam 
394 crest accelerations (Pelecanos et al., 2016). However, the stress and strain of the upstream dam body 395 may be sensitive to hydrodynamic pressure (Pelecanos et al., 2020). To simulate the DRF dynamic 396 interaction system, fluid elements, which represent a linearly elastic inviscid, irrotational, and 397 compressible medium, are used to model the reservoir. In addition, the coupled Lagrangiann 398 formulation of FE method is directly conduct for seismic dynamic analysis of interacting DRF systems.

399 As illustrated in Fig. 11(a), the upstream face of the reservoir is set as non-reflecting boundary 400 condition to enable energy dissipation during the dynamic analysis process. The direction normal 401 displacement is assumed to simulate the interface between the reservoir and the dam following the 402 recommendations of Wang et al. (2018). At the dam - foundation interface, the reservoir is tied with 403 the foundation of the dam. The material mechanical properties of the fluid element can be found in our 404 previous work of Wang et al. (2015). The typical damping ratio for DRF dynamic interaction system 405 is assumed as 5\% in time - history dynamic analyses. Rayleigh damping, calculated by two parameters 406 obtained from modal damping ratios of the DRF dynamic interaction system, is considered in time407 history dynamic analyses.

\section{4.3. Seismic wave input mechanism}

An effective and reasonable GM input mechanism is required to ensure the stability and accuracy

410 of the numerical results before the dynamic analysis of Dashimen dam. Recently, the methodology in

411 which the near-field numerical calculation region is extracted from a semi-infinite elastic medium is

412 commonly applied on the hydraulic engineering. Liu et al. (2006) proposed widely employed viscous-

413 spring artificial boundary (VASB) with good high-frequency and low-frequency stability. Moreover, 
414 the VSAB can absorb scattered waves and reflect the elastic recovery feature of a semi-infinite medium

415 under strong GM excitation. The VSAB is generally employed on the truncated boundary of 416 foundation, as display on Fig. 11(a). On the other hand, the horizontal and vertical component of GM

417 excitation can be simulated by converting the time - history of GM into time - history of equivalent

418 nodal forces of truncated boundary nodes according to the work of Liu et al. (2006). The equivalent

419 nodal force $f_{l i}$ of truncated boundary nodes $l$ in direction can be derived as follows:

$$
f_{l i}=K_{l i} d_{l i}^{f}+C_{l i} v_{l i}^{f}+\sigma_{l i}^{f}
$$

421 where $K_{l i}$ and $C_{l i}$ represents the parameter of stiffness and damping coefficients for spring-damper;

$422 d_{l i}^{f}, v_{l i}^{f}$ and $\sigma_{l i}^{f}$ represent displacement vector, velocity vector, stress vector at the truncated

423 boundary node 1 , respectively (Du and Zhao, 2006). The detailed seismic wave input method and

424 validation cases in the infinite elastic medium can be found in our previous work (Benbo Sun et al., $4252020 b, 2020 c, 2020 a)$.

426 5. Fragility analysis and discussion

\section{$427 \quad 5.1$ Relative settlement ratio index}

Results of the dynamic analyses show that the ID of strong GMs take a significant effect on the

429 RSR of a high ACCRD, as shown in Fig. 12. This figure shows the RSR of a high ACCRD under long

430 - duration is mostly greater than that under short - duration. To interrogate the differences in the RSR

431 of a high ACCRD under shorter duration and longer duration GMs, the mean value of the RSR under

432 different seismic intensities is compared in Fig. 13. As displayed in Fig. 13, the difference between

433 short - duration GMs and long - duration GMs increases as the seismic intensity increases. This 
434 observation means that the coupling of high intensity GMs and long - duration may induce serious 435 damage for a high ACCRD.

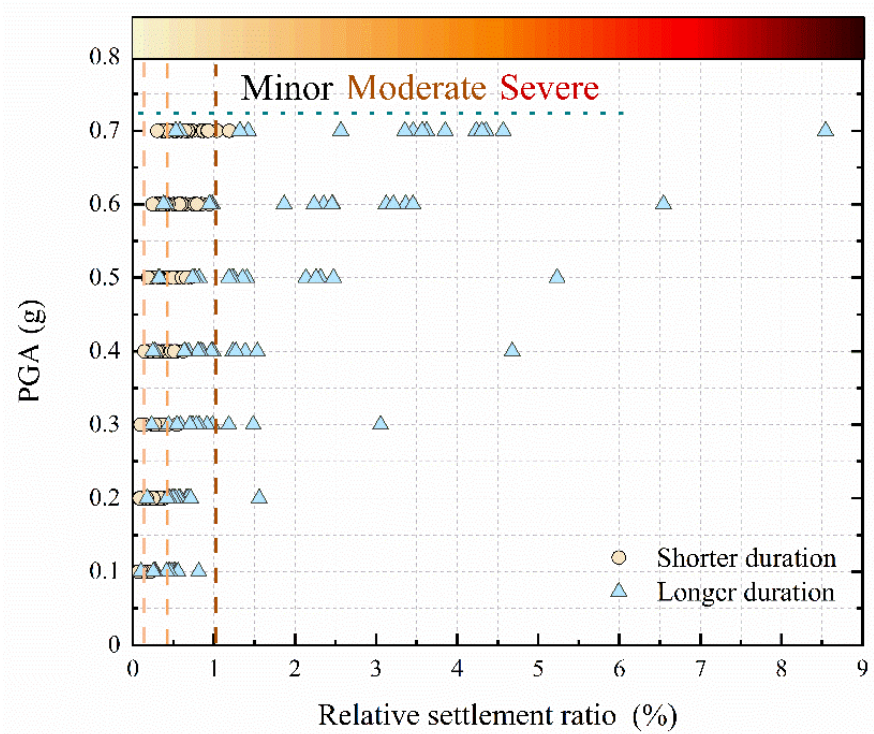

Fig. 12. The RSR of multiple strip response under different seismic intensities.

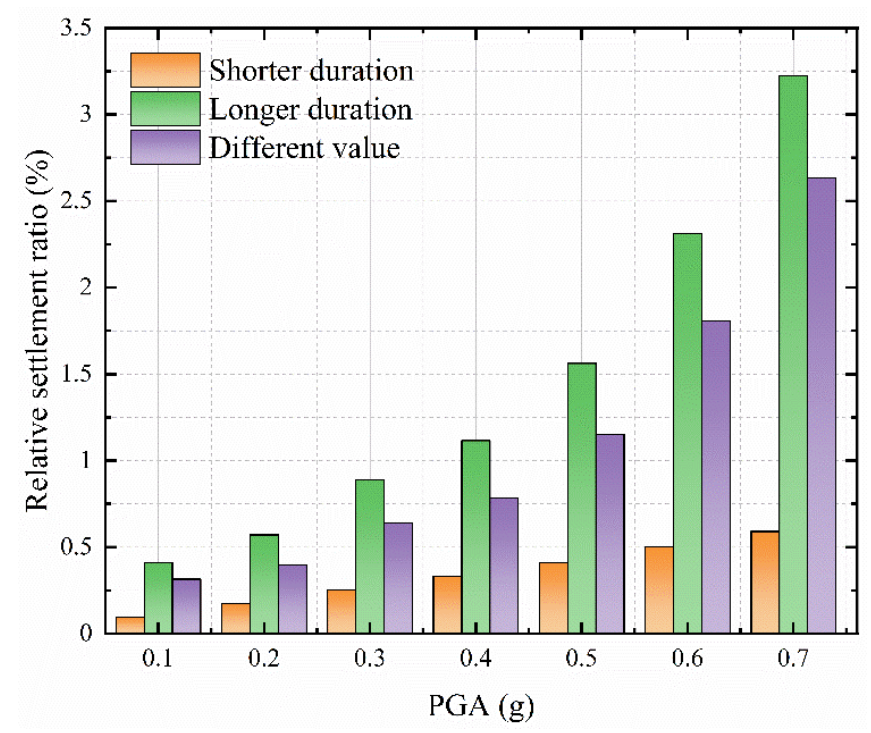

Fig. 13. Mean value of RSR.

The seismic fragility curves for the minor, moderate and severe performance levels obtained from

441 Eq. (7) are given in Fig. 14. For simplicity of illustration, this figure provides presents the comparison

442 of seismic fragility curves of short - and long - duration GMs for different performance levels. For the

443 same performance levels, the seismic fragility curve for the short - duration is uniformly situated to 
444 the right of the seismic fragility curve of long - duration, meaning the increasing POE when the high

445 ACCRD is excited by long - duration GMs. Currently, the seismic design of high dams generally

446 consider two seismic levels to assure structural safety, containing the operating basis earthquake (OBE)

447 and the maximum credible earthquake (MCE). For this high ACCRD, the OBE and MCE stipulated in

448 the actual engineering project situation is defined as $0.4 \mathrm{~g}$ PGA and 0.54g PGA, respectively. Figure

44915 further list the POE of RSR in different performance level. The highest POE is given by long -

450 duration GMs of the order of $100 \%$ in Minor damage, $95 \%$ in moderate damage, $54 \%$ in severe damage

451 under MCE excitation.

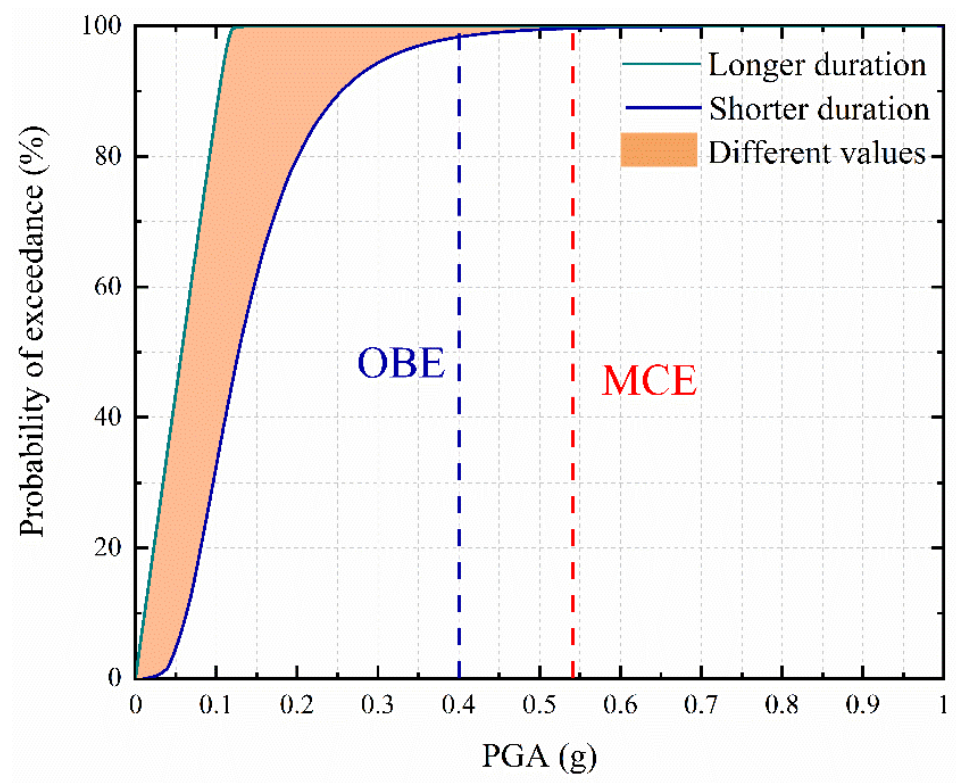

(a) Minor 


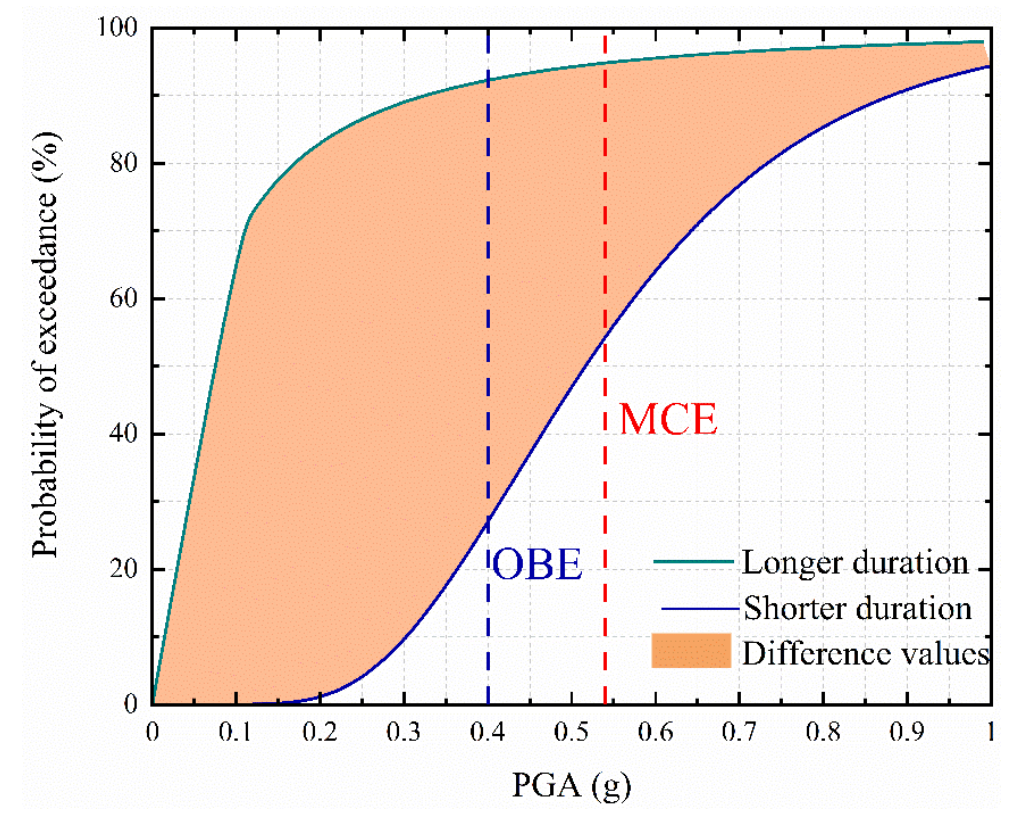

(b) Moderate

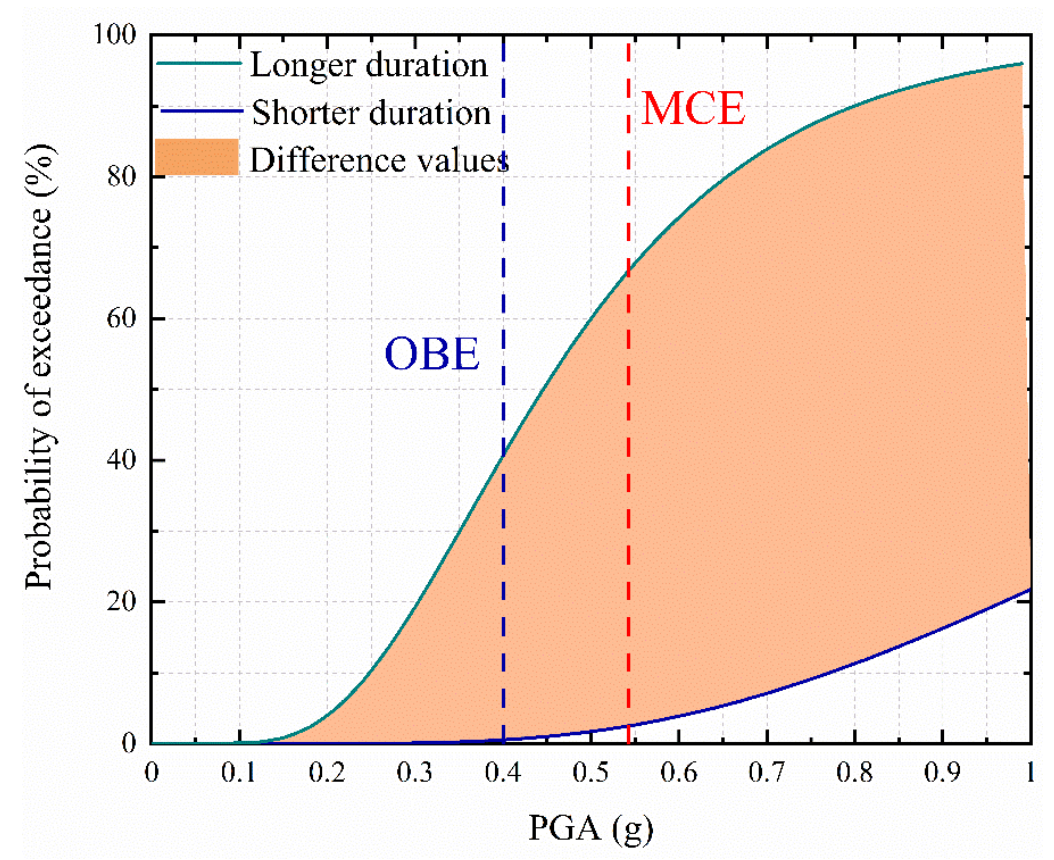

(c) Severe

458 Fig. 14. Comparison of fragility curves of short - and long - duration GMs for different performance levels: (a) Minor 


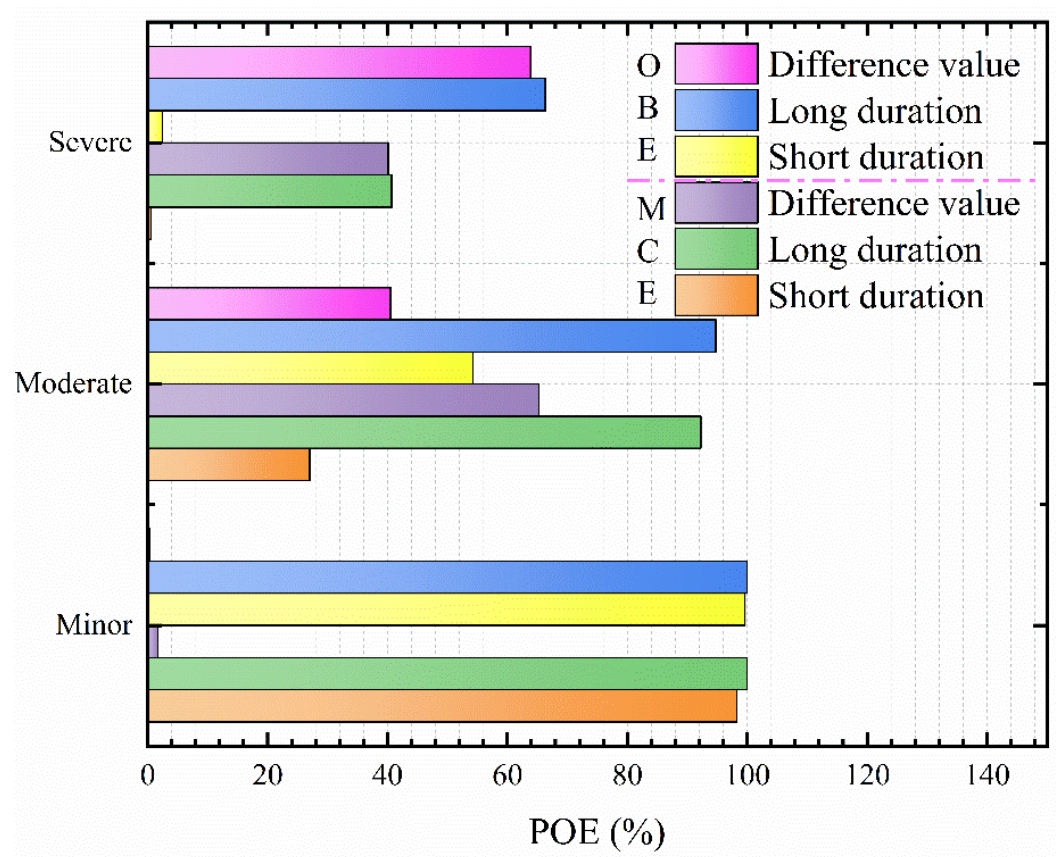

Fig. 15. The POE of different performance levels of RSR under OBE and MCE.

\subsection{The stress demand-capacity ratios and cumulative inelastic duration index}

The seismic performance evaluation based on the DCR-CID is utilized to assess the performance

464 levels of the ACCRD subjected to short - and long - duration GMs. Figures 16(a) presents the 465 maximum principle tensile stress time histories for short - and long - duration GMs with a PGA level 466 of $0.5 \mathrm{~g}$. The corresponding performance evaluation curves are illustrated in Fig. 16(b). It is clear from

467 Fig. 16(a) that the long - duration records make the number of cycles that excess of the tensile strength 468 of the asphalt concrete greater than the short - duration. Results in Fig, 16(b) display that the stress 469 DCR exceed 1 or 2 and the CID under long - duration GMs are significantly greater than the short 470 duration. In addition, the DCR-CID under short - duration GMs with a PGA level of $0.5 \mathrm{~g}$ are in the

471 range of low to moderate damage. The DCR-CID seismic fragility curves obtained at each damage

472 levels for the asphalt concrete core is shown in Fig. 17. It is evident from this figure that the effect of 
473 GMD on the seismic fragility curve of the high ACCRD is maximal for the two damage levels, while

474 a significantly difference value of POE can be found. Overall, the probability of exceeding the each

475 performance levels under long - duration is greater that the POE under short - duration. Furthermore,

476 the probability of exceeding the severe performance level under strong GMs is below the $50 \%$, which

477 means the asphalt concrete core can perform its engineering function under extremely earthquake

478 excitation. For simplicity of illustrate the difference characteristic of short - duration and long -

479 duration, Fig. 18 list the POE of two performance levels of DCR-CID under OBE and MCE.

480 Comparing short - duration and long - duration under OBE and MCE in Fig. 18 shows that they are

481 generally different from each other. For instance, the difference value between short - duration and

482 long - duration for POE of moderate damage is $20.2 \%$ at OBE, 20.8\% at MCE, corresponding the POE

483 of severe damage is $9.2 \%$ at $\mathrm{OBE}, 12.8 \%$ at MCE.

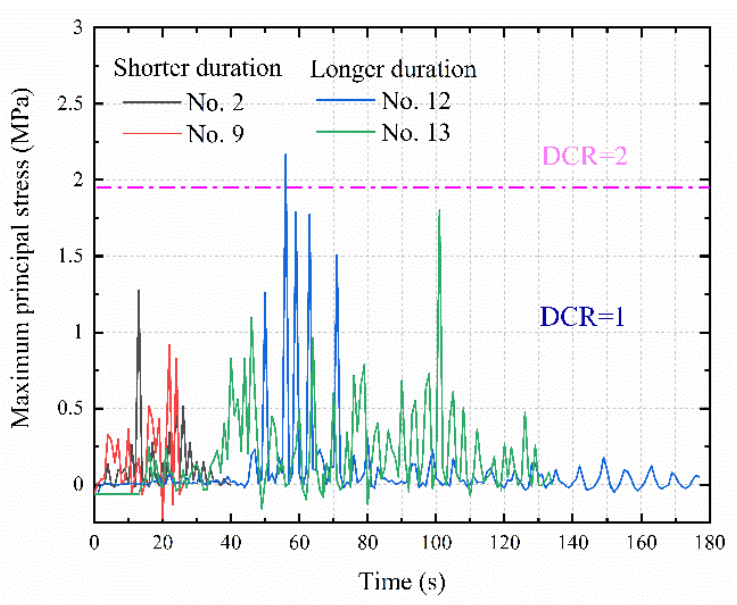

(a) Time histories of maximum principal stress

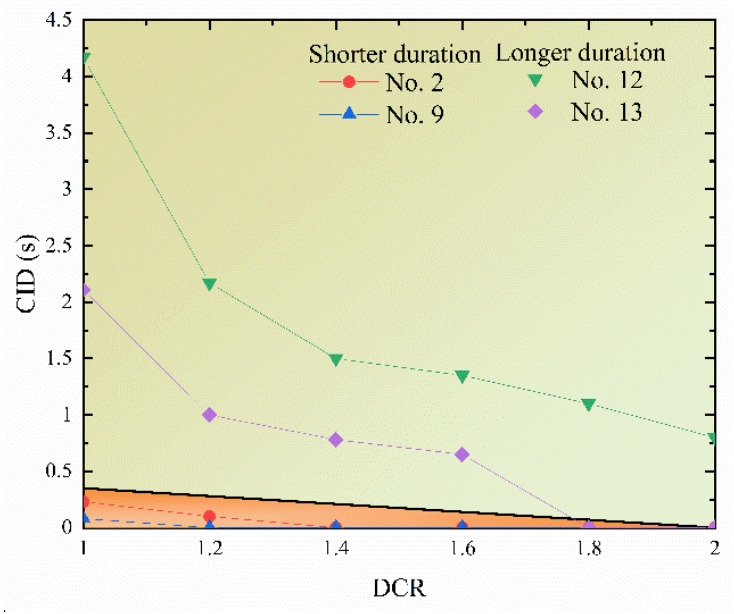

(b) Performance assessment curves

486 Fig. 16. Time histories of maximum principal stress and performance assessment curves for short - and long - duration 


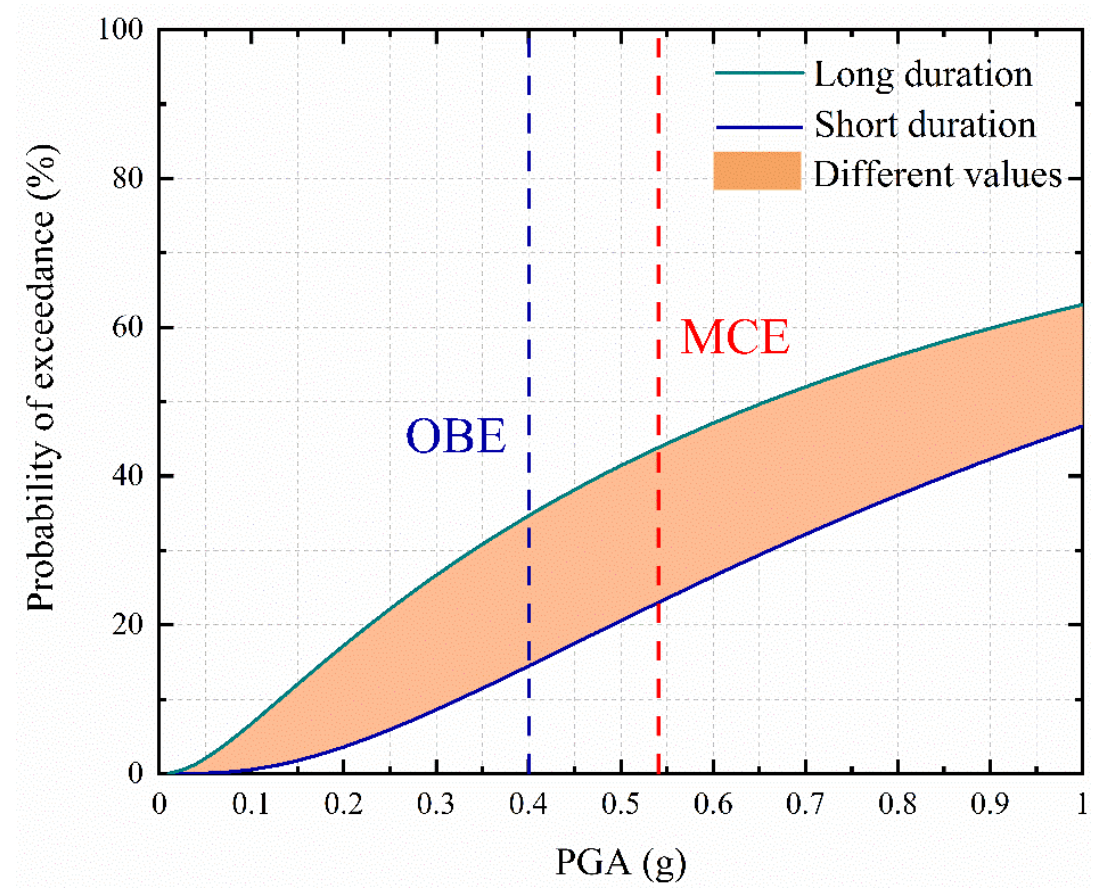

(a) Moderate

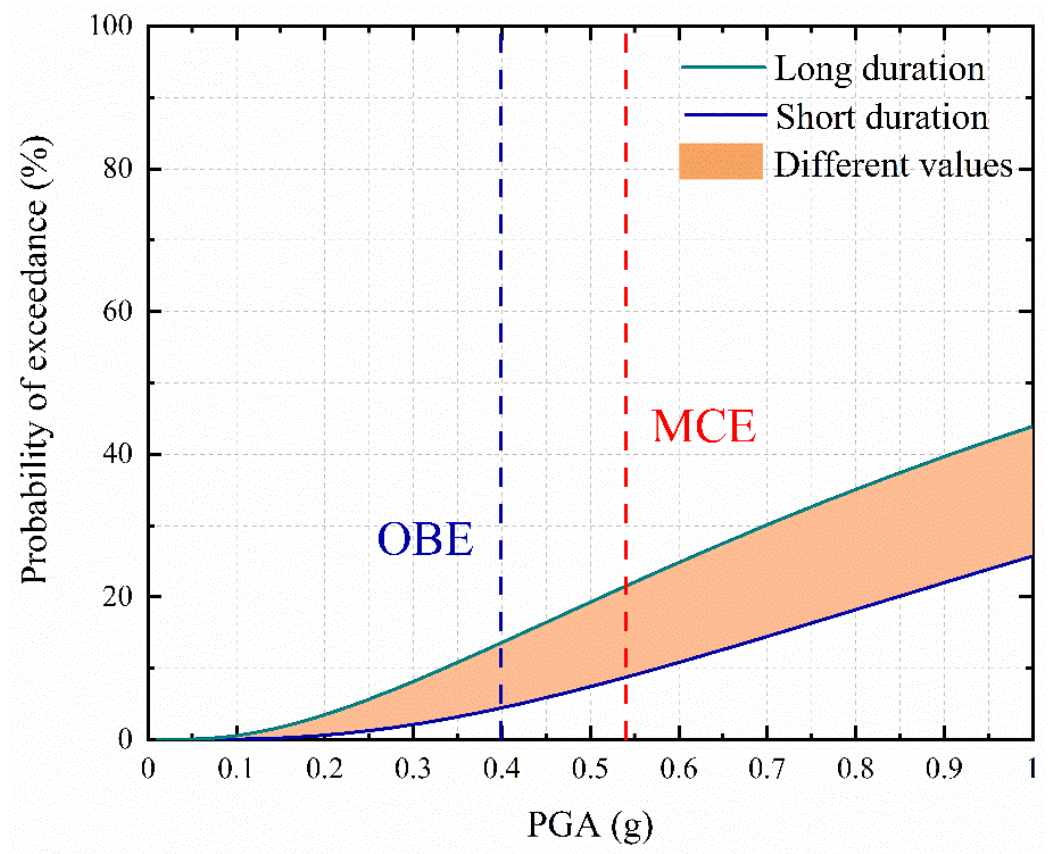

(b) Severe

Fig. 17. Seismic fragility curves with short - and long - duration GMs for (a) moderate; (b) severe. 


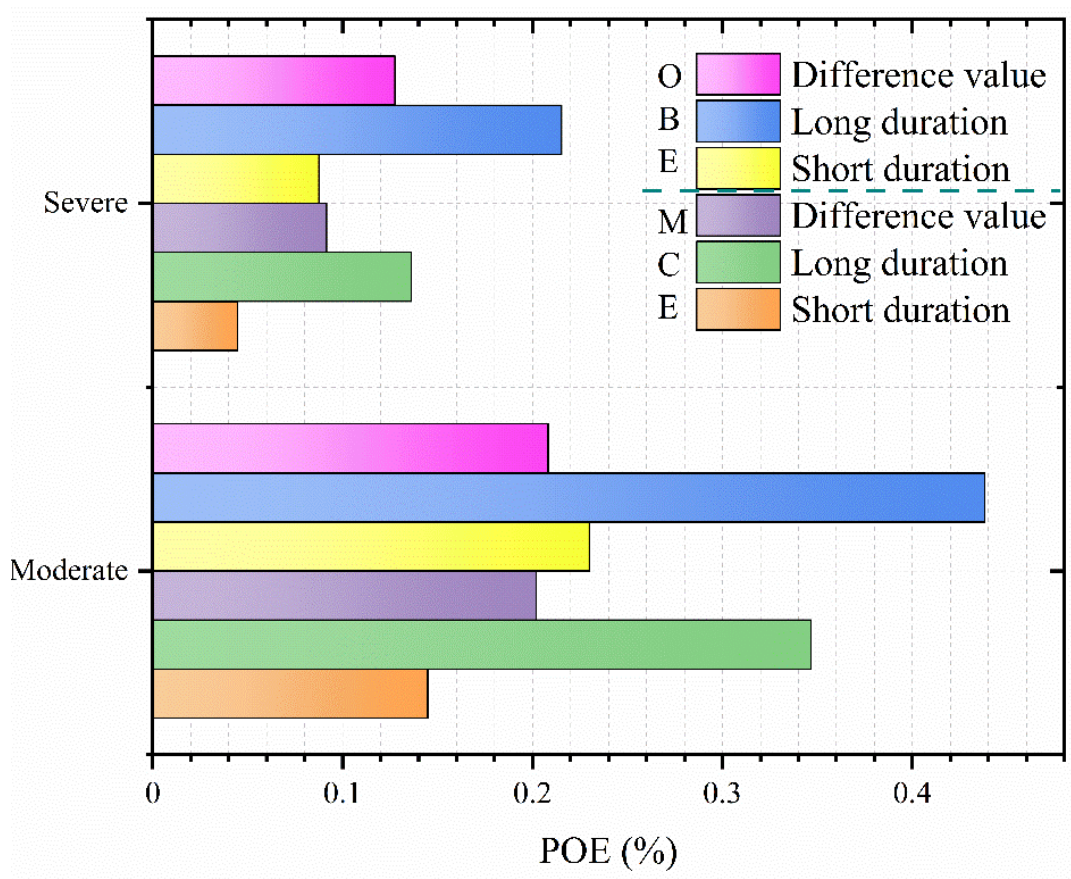

Fig. 18. The POE of different performance levels of RSR under OBE and MCE.

\section{Summary and conclusions}

This study entirely studied the impact of short - and long - integrated duration (ID) on the seismic

497 fragility analysis (FR) of a high asphalt concrete core rockfill dam (ACCRD) considering dam -

498 reservoir - foundation (DRF) dynamic interaction system. A series of seismic dynamic analysis of

499 finite element model were conducted to generate 322 numerical results to determine the seismic

500 fragility curves of a high ACCRD via coupling multiple stripe analysis and maximum likelihood 501 estimate.

502 In this particular study, the developed multiple stripe data showed that the relative settlement ratio

503 (RSR) of a high ACCRD is more vulnerable to moderate damage or severe damage when subjected to

504 longer duration. Furthermore, the results of the system fragility curves indicate that for damage states

505 for which the high ACCRD behaves under strong GMs, there is significantly effect due to the different 
506 ID on the fragility curves and risk. The damage state of a high ACCRD under shorter duration exhibit

507 smaller seismic fragilities. Such phenomenon is explained by the fact that for the operating basis 508 earthquake (OBE) or the maximum credible earthquake (MCE), the longer duration may trigger severe 509 damage of a high ACCRD.

510 The impact of ID on the stress DCR and CID demonstrates that the stress DCR exhibits sensitivity 511 to the longer duration, while the CID also shows relatively strong sensitivity to the longer duration. It 512 is reasonable that the longer duration, the greater DCR-CID, since the performance index is related to 513 the duration of cycles exceeding the tensile strength of the asphalt concrete core. Similarly, the 514 developed seismic fragility curves for the asphalt concrete core under longer duration exhibited 515 significantly higher POE than shorter duration. In addition, the difference value of POE between short 516 - duration and long - duration is increase along with the increase seismic intensity. The study provides 517 important insight into the seismic behavior of the high ACCRD and highlights the need for further 518 development of seismic design codes in consideration of the impact of ground motion duration, 519 frequency, amplitude.

520 Finally, several restrictions of the present study should be paid more attention. Among the effect 521 of real environment, the dam-reservoir-foundation dynamic interaction system is more complex, so 522 only the effect of hydrodynamic pressure is considered. Further, the tensile strength of asphalt concrete 523 is approximately determined according the work of Ghanaat (2004). Further research should consider 524 the shaking model test and numerical analysis with more than two performance indictors or with 525 different elastic-plastic analysis combinations of the multi-field coupling approach. 
527 The authors gratefully appreciate the support from the National Natural Science Foundation of 528 China (No.51979188 \& No.51779168), National Key Research and Development Program of China 529 (No. 2018YFC0406901)

\section{Declarations}

531 Conflict of interest The authors declare no conflict of interest.

\section{References}

533 Ardebili, M. H. and Mirzabozorg H. (2012) Effects of near-fault ground motions in seismic performance evaluation

534 of a symmetric arch dam. Soil mechanics and foundation engineering, 49(5), 192-199.

535 Baker, J. W. (2015) Efficient analytical fragility function fitting using dynamic structural analysis,” Earthquake 536 Spectra, 31(1), 579-599.

537 Barbosa, A. R., Ribeiro, F. L., and Neves, L. A. (2017) Influence of earthquake ground - motion duration on damage 538 estimation: application to steel moment resisting frames. Earthquake Engineering \& Structural Dynamics, 46(1), 2753949.

540 Baziar, M. H., Salemi, S. H., and Merrifield, C. M. (2009) Dynamic centrifuge model tests on asphalt-concrete core 541 dams. Geotechnique, 59(9), 763-771.

542 Bolt, B.A. (1973) Duration of strong ground motion. in: Proceedings of the 5th World Conference on Earthquake 543 Engineering, pp. 1304-1313.

544 Bommer, J. J., and Martinez-Pereira, A. (1999) The effective duration of earthquake strong motion. Journal of 545 earthquake engineering, 3(02), 127-172. 
546 Bommer, J. J., Stafford, P. J., and Alarcón, J. E. (2009) Empirical equations for the prediction of the significant,

547 bracketed, and uniform duration of earthquake ground motion. Bulletin of the Seismological Society of America, 548 99(6), 3217-3233.

549 Celik, O. C., and Ellingwood, B. R. (2010) Seismic fragilities for non-ductile reinforced concrete frames-Role of 550 aleatoric and epistemic uncertainties. Structural Safety, 32(1), 1-12.

551 DU, X. L. and ZHAO, M. (2006) Analysis method for seismic response of arch dams in time domain based on 552 viscous-spring artificial boundary condition. Journal of Hydraulic Engineering, 9, 1063-1069. (in Chinese)

553 Duncan, J. M., and Chang, C. Y. (1970) Nonlinear analysis of stress and strain in soils. Journal of Soil Mechanics \& 554 Foundations Div.

555 Fajfar, P. (2000) A nonlinear analysis method for performance - based seismic design. Earthquake spectra, 16(3), $556 \quad 573-592$.

557 Feng, S., Wang, W., Hu, K., and Höeg, K. (2020) Stress-strain-strength behavior of asphalt core in embankment dams 558 during construction. Construction and Building Materials, 259, 119706.

559 Ghanaat, Y. (2004) Failure modes approach to safety evaluation of dams. in: Proceedings of the 13th World 560 Conference on earthquake engineering.

561 Green, R. A., and Terri, G. A. (2005) Number of equivalent cycles concept for liquefaction evaluations—-Revisited. 562 Journal of Geotechnical and Geoenvironmental Engineering, 131(4), 477-488.

563 Hardin, B. O., and Drnevich, V. P. (1972) Shear modulus and damping in soils: design equations and curves. Journal 564 of Soil Mechanics and Foundations Div, 98(sm7).

565 Huang, J. Q., Du, X. L., Zhao, M., and Zhao, X. (2017) Impact of incident angles of earthquake shear (S) waves on 566 3-D non-linear seismic responses of long lined tunnels. Engineering Geology, 222, 168-185. 
567 Chunlou, J., Songyou, X., and Desheng, D. (1995) Dynamic Analysis of Asphalt Concrete Core Rockfill Dams on 568 Deep Overburden. JOURNAL OF HOHAI UNIVERSITY (NATURAL SCIENCES), 5

569 Ji, H. (2006) 3-D FEM Dynamic Analysis on Asphalt Concrete Core-wall Rockfill Dam Built on Deep Overburden 570 Layers." Hohai University.

571 Jun-shuai, W. U., and JIANG, P. (1992) Dynamic shearing characteristics of soil-concrete interface. Chinese Journal 572 of Geotechnical Engineering, 14(2), 61-66.

573 Kitayama, S., and Constantinou, M. C. (2020) Implications of strong earthquake ground motion duration on the 574 response and testing of seismic isolation systems. Earthquake Engineering \& Structural Dynamics.

575 Kong, X. J., Yu, Y., and Zou, D. G. (2014) 3D FE static and dynamic analysis of rockfill dam with asphalt concrete 576 core. J. Dalian Univ. Technol, 54(2), 197-203.

577 Lee, J., \& Fenves, G. L. (1998) Plastic-damage model for cyclic loading of concrete structures. Journal of engineering 578 mechanics, 124(8), 892-900.

579 Li, Y. long, Tang, W., Wen, L. feng, Wu, H., (2020) Dam seismic deformation evaluation method of asphalt concrete 580 core rockfill dam and its reliability analysis. Journal of Hydraulic Engineering, 51(5), 558-580.

581 Liu, J., Du, Y., Du, X., Wang, Z., and Wu, J. (2006) 3D viscous-spring artificial boundary in time domain. Earthquake 582 Engineering and Engineering Vibration, 5(1), 93-102.

583 Lubliner, J., Oliver, J., Oller, S., and Oñate, E. (1989) A plastic-damage model for concrete. International Journal of 584 solids and structures, 25(3), 299-326.

585 Ning Z, Liu Y, Wang W. (2021) Compressive Behavior of Hydraulic Asphalt Concrete under Different Temperatures 586 and Strain Rates. Journal of Materials in Civil Engineering, 2021, 33(4): 04021013.

587 Ou, Y. C., Song, J., Wang, P. H., Adidharma, L., Chang, K. C., and Lee, G. C. (2014) Ground motion duration effects 
588 on hysteretic behavior of reinforced concrete bridge columns. Journal of Structural Engineering, 140(3), 04013065.

589 Pang, R., Xu, B., Kong, X., and Zou, D. (2018) Seismic fragility for high CFRDs based on deformation and damage

590 index through incremental dynamic analysis. Soil Dynamics and Earthquake Engineering, 104, 432-436.

591 Pelecanos, L., Kontoe, S., and Zdravković, L. (2020) The effects of dam-reservoir interaction on the nonlinear

592 seismic response of earth dams. Journal of Earthquake Engineering, 24(6), 1034-1056.

593 Pelecanos, L., Kontoe, S., and Zdravković, L. (2016) Dam-reservoir interaction effects on the elastic dynamic

594 response of concrete and earth dams. Soil Dynamics and Earthquake Engineering, 82, 138-141.

595 Raghunandan, M., Liel, A. B. (2013) Effect of ground motion duration on earthquake-induced structural collapse.

596 Structural Safety, 41, 119-133.

597 Serff, N., Seed, H. B., Makdisi, F. I., and Chang, C. Y. (1976) Earthquake-induced deformations of earth dams.

598 University of California, Berkeley.

599 Sun, B., Zhang, S., Cui, W., Deng, M., and Wang, C. (2020) Nonlinear dynamic response and damage analysis of

600 hydraulic arched tunnels subjected to P waves with arbitrary incoming angles. Computers and Geotechnics, 118,

$601 \quad 103358$.

602 Sun, B., Zhang, S., Deng, M., and Wang, C. (2020) Inelastic dynamic response and fragility analysis of arched

603 hydraulic tunnels under as-recorded far-fault and near-fault ground motions. Soil Dynamics and Earthquake

604 Engineering, 132, 106070.

605 Sun, B., Zhang, S., Deng, M., and Wang, C. (2020) Nonlinear dynamic analysis and damage evaluation of hydraulic

606 arched tunnels under mainshock-aftershock ground motion sequences. Tunnelling and Underground Space

607 Technology, 98, 103321.

608 Sun, B., Zhang, S., Deng, M., and Wang, C. (2020) Inelastic dynamic response and fragility analysis of arched 
609 hydraulic tunnels under as-recorded far-fault and near-fault ground motions. Soil Dynamics and Earthquake

610 Engineering, 132, 106070

611 Swaisgood, J. R. (2003) Embankment dam deformations caused by earthquakes. in: Pacific conference on earthquake 612 engineering (pp. pp-014).

613 Trifunac, M. D., Brady, A. G. (1975) A study on the duration of strong earthquake ground motion. Bulletin of the 614 Seismological Society of America, 65(3), 581-626.

615 Vamvatsikos, D., Cornell, C. A. (2004) Applied incremental dynamic analysis. Earthquake Spectra, 20(2), 523-553.

616 Wang, D. B., Liu, H. L., Yu, T., and Yang, G. (2015) Seismic fragility analysis for earth-rockfill dams based on 617 deformation. Chinese Journal of Geotechnical Engineering, 12(22), 54-61.

618 Wang, G., Wang, Y., Lu, W., Yan, P., and Chen, M. (2020) Earthquake Direction Effects on Seismic Performance of 619 Concrete Gravity Dams to Mainshock-Aftershock Sequences. Journal of Earthquake Engineering, 24(7), 1134-1155.

620 Wang, G., Wang, Y., Zhou, W., and Zhou, C. (2015) Integrated duration effects on seismic performance of concrete 621 gravity dams using linear and nonlinear evaluation methods. Soil Dynamics and Earthquake Engineering, 79, 223622236.

623 Wang, G., Zhang, S., Wang, C., and Yu, M. (2014) Seismic performance evaluation of dam-reservoir-foundation 624 systems to near-fault ground motions. Natural hazards, 72(2), 651-674.

625 Wang, W., Höeg, K. (2016) Simplified material model for analysis of asphalt core in embankment dams. Construction 626 and Building Materials, 124, 199-207.

627 Wang, W., Höeg, K., and Zhang, Y. (2010) Design and performance of the Yele asphalt-core rockfill dam. Canadian 628 geotechnical journal, 47(12), 1365-1381.

629 Wang, Z. Z., Jiang, Y. J., and Zhu, C. A. (2019) Seismic energy response and damage evolution of tunnel lining 
630 structures. European Journal of Environmental and Civil Engineering, 23(6), 758-770.

631 Xu, B., Pang, R., and Zhou, Y. (2020) Verification of stochastic seismic analysis method and seismic performance 632 evaluation based on multi-indices for high CFRDs. Engineering Geology, 264, 105412.

633 Zhang, S., Wang, G., Pang, B., Du, C. (2013) The effects of strong motion duration on the dynamic response and 634 accumulated damage of concrete gravity dams. Soil Dynamics and Earthquake Engineering, 45, 112-124.

635 Zhu-Jiang, S. H. E. N., and Gang, X. U. (1996) Deformation behavior of rock materials under cyclic loading. Journal 636 of Nanjing Hydraulic Research Institute, 2, 143-150. 


\section{Figures}
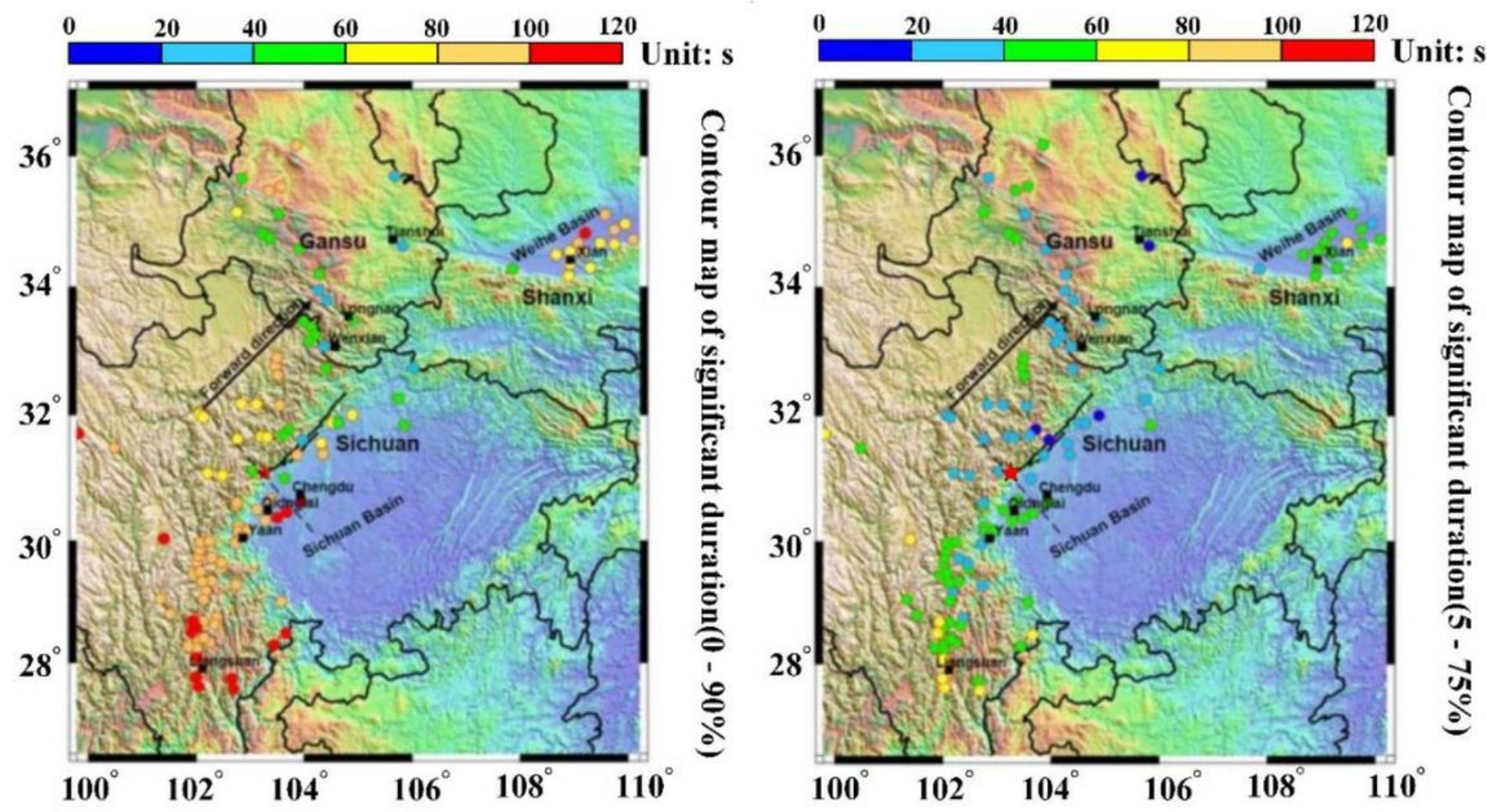

Figure 1

Spatial distribution of significant duration recorded from Wenchuan earthquake (Mw7.9, 2008). (a) 0-90\% significant duration; (b) 5-75\% significant duration. Note: The designations employed and the presentation of the material on this map do not imply the expression of any opinion whatsoever on the part of Research Square concerning the legal status of any country, territory, city or area or of its authorities, or concerning the delimitation of its frontiers or boundaries. This map has been provided by the authors. 

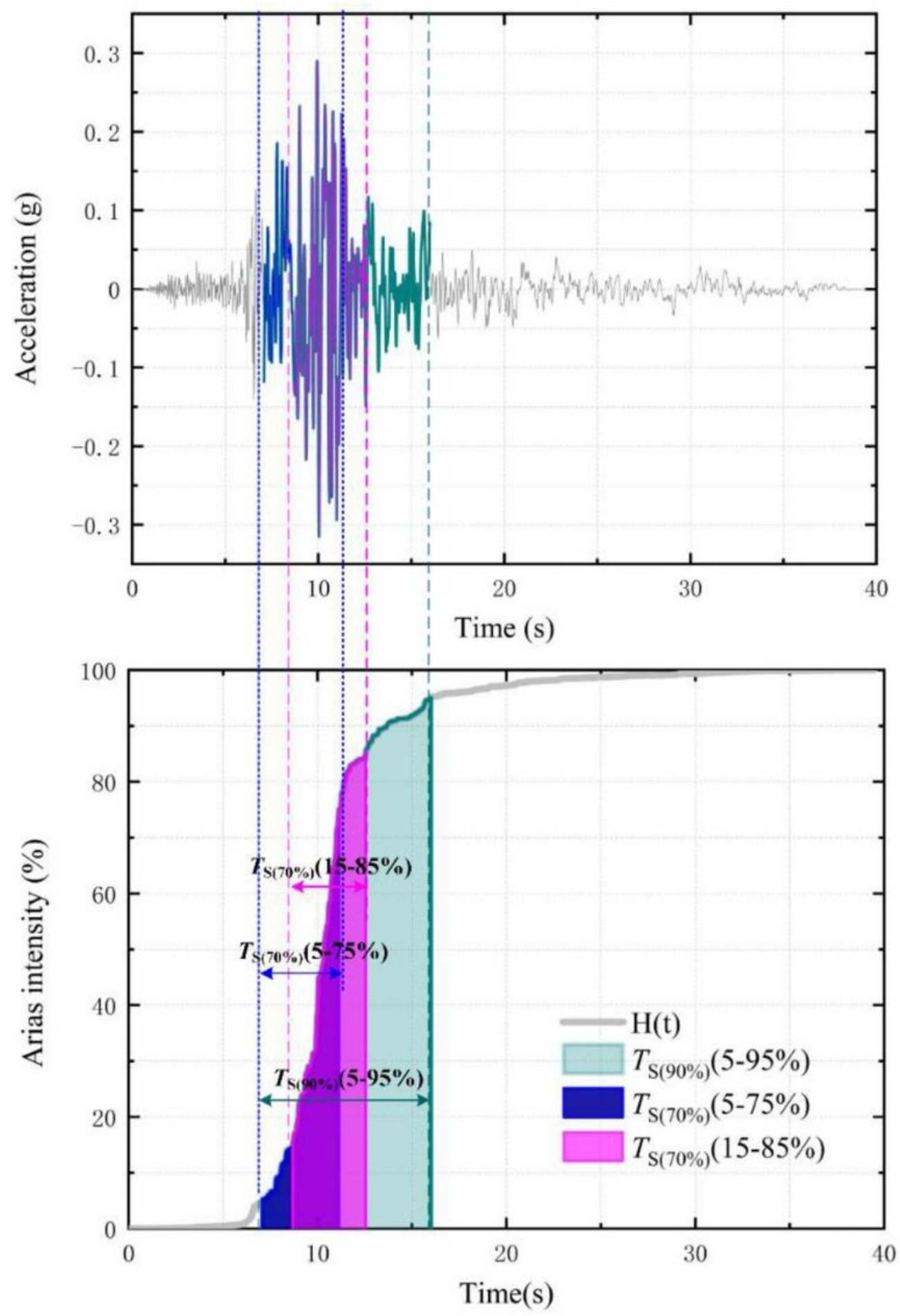

Figure 2

The husid diagram of three SDs of an as-record accelerogram. 


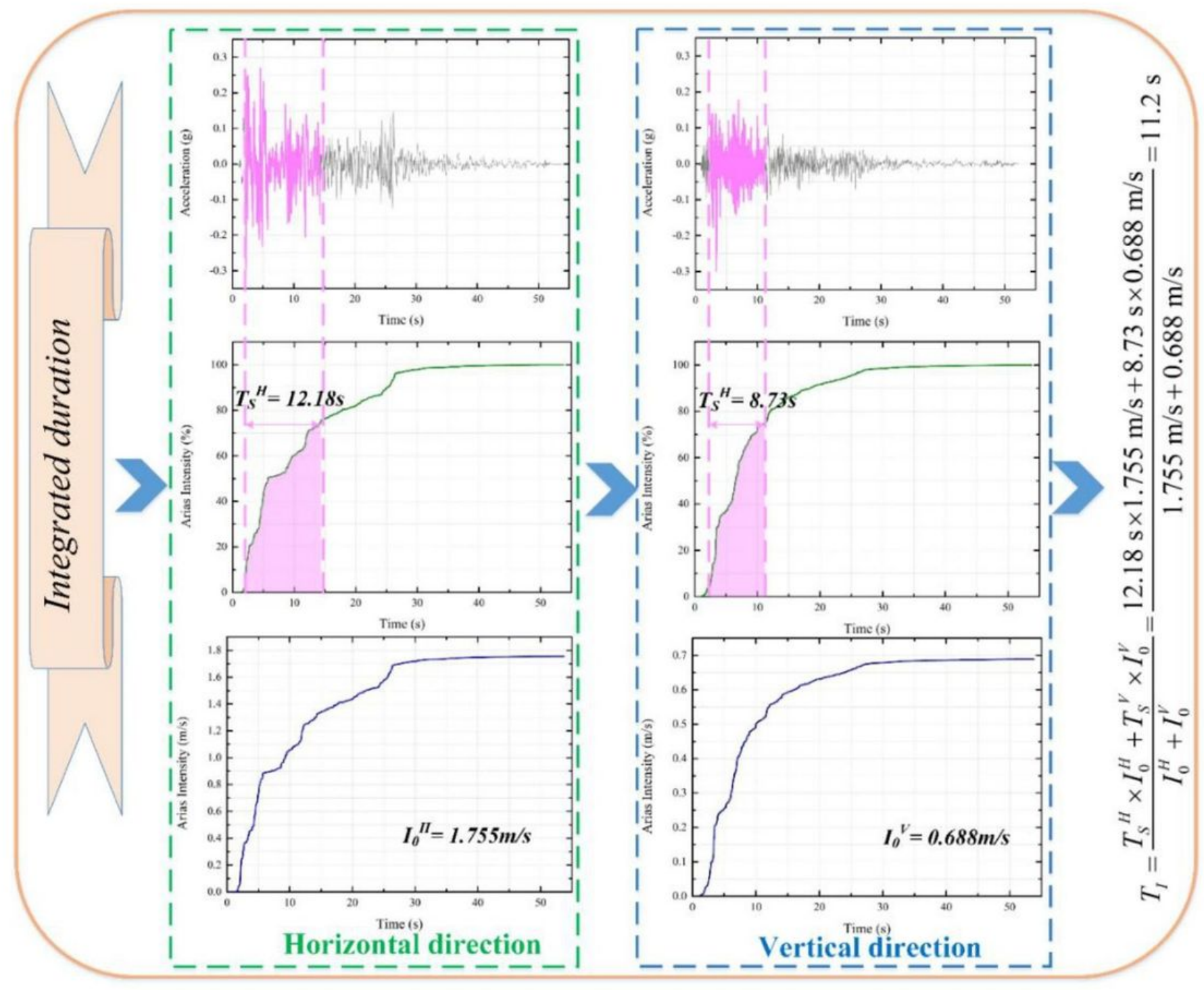

Figure 3

Calculation progress of ID based on SD (5-75\%). 


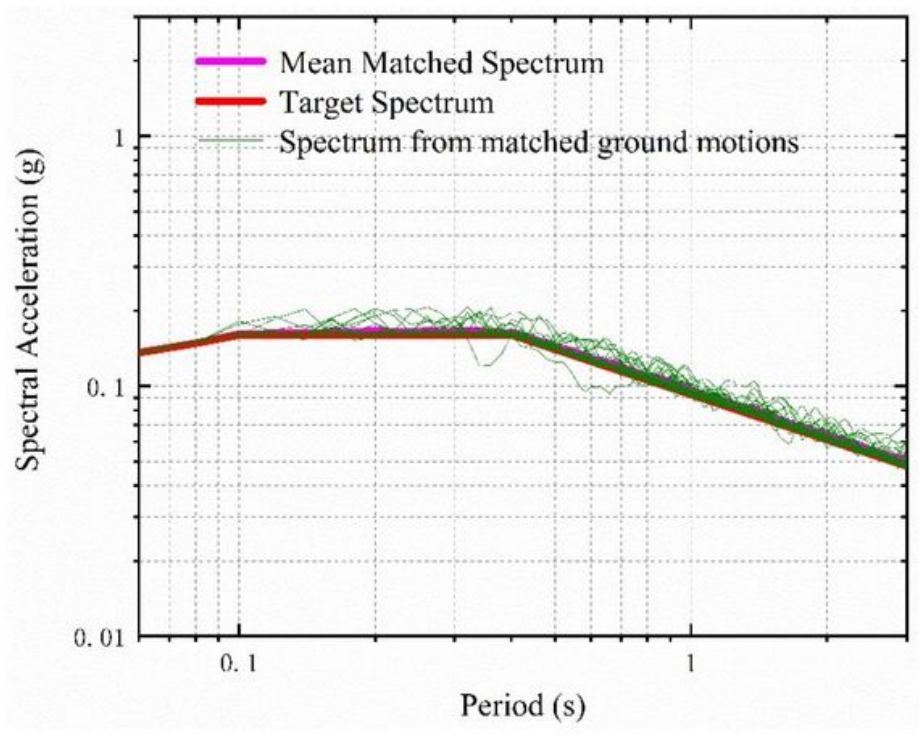

(a)

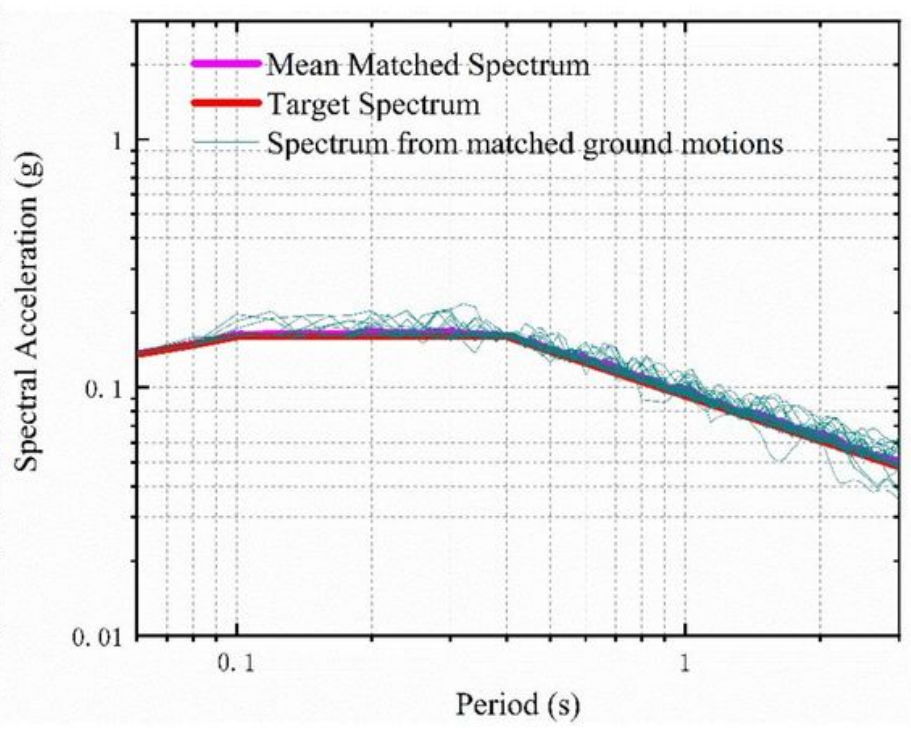

(b)

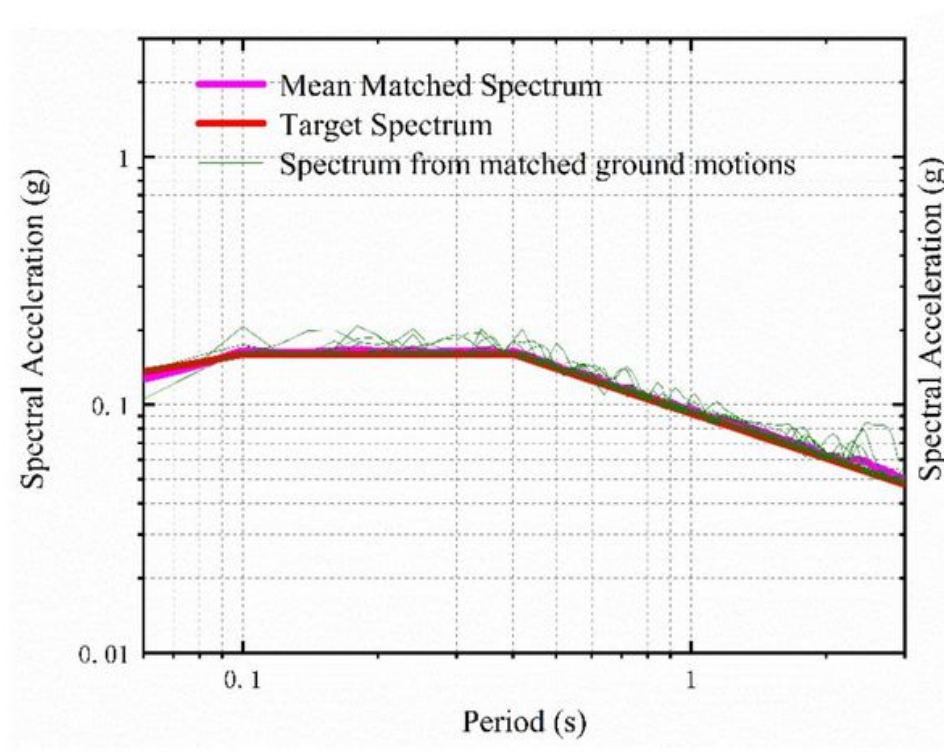

(c)

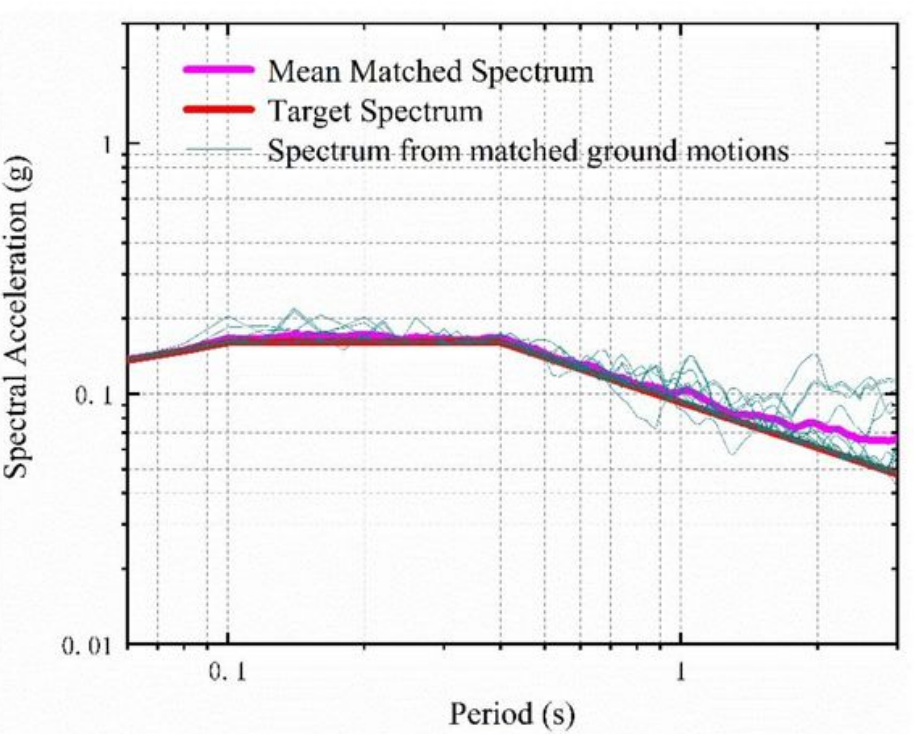

(d)

\section{Figure 4}

Comparison of the adjusted response spectra of short - and long - duration GMs: (a) horizontal short duration; (b) vertical direction short - duration; (c) horizontal long - duration; (b) vertical direction long duration. 


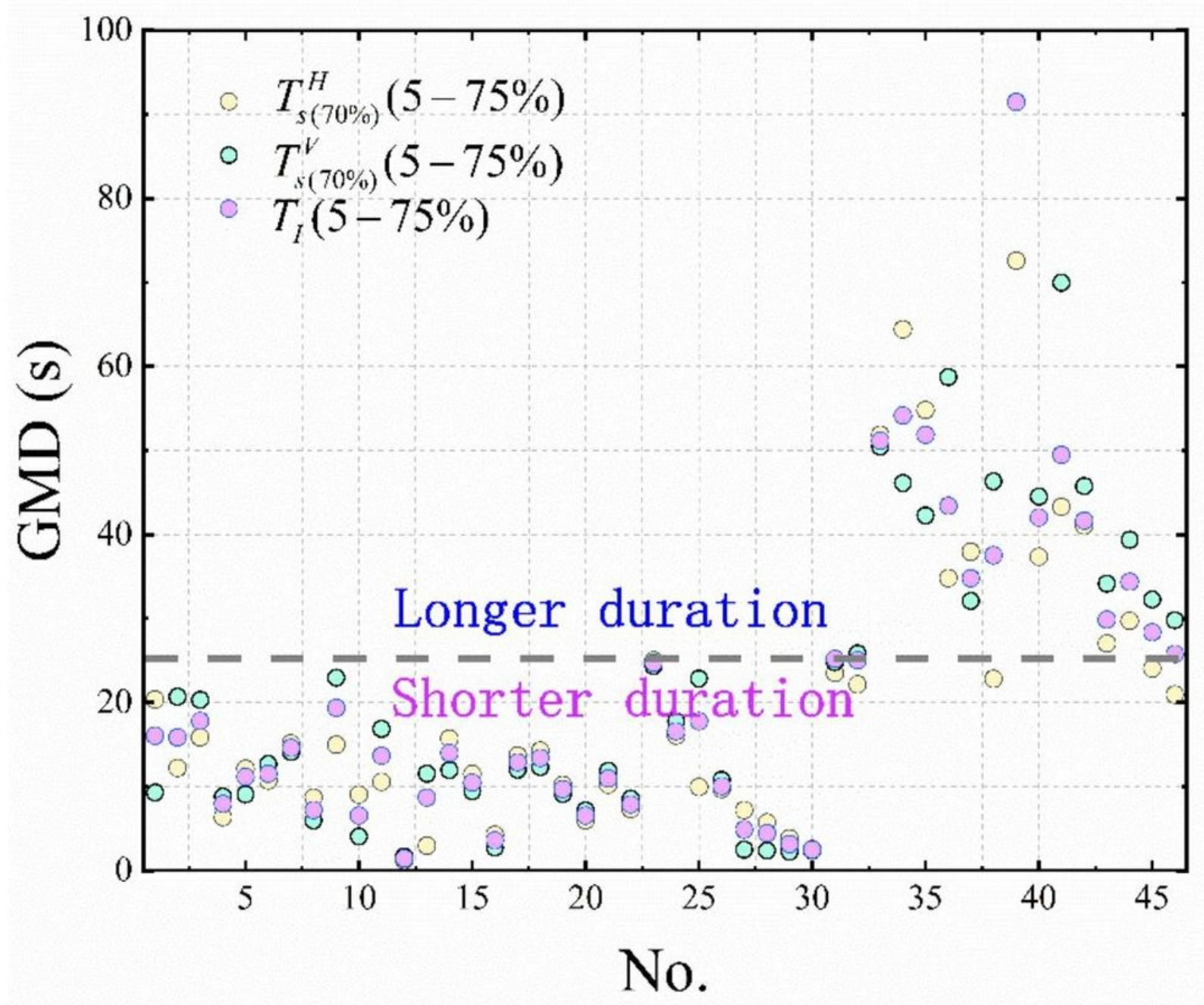

Figure 5

Distribution of GMD in database after matching spectral acceleration. 


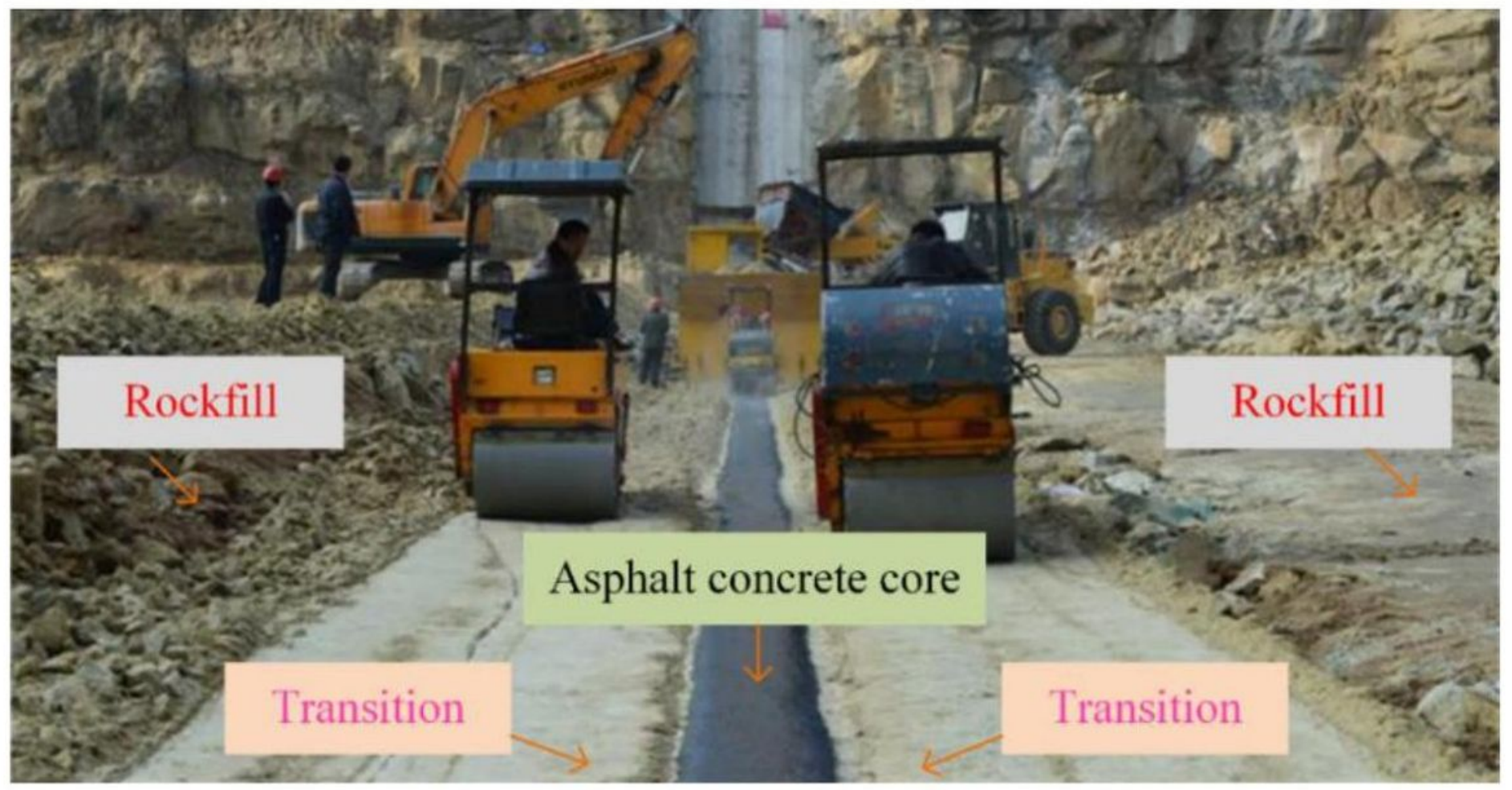

Figure 6

Construction of high ACCRD. 


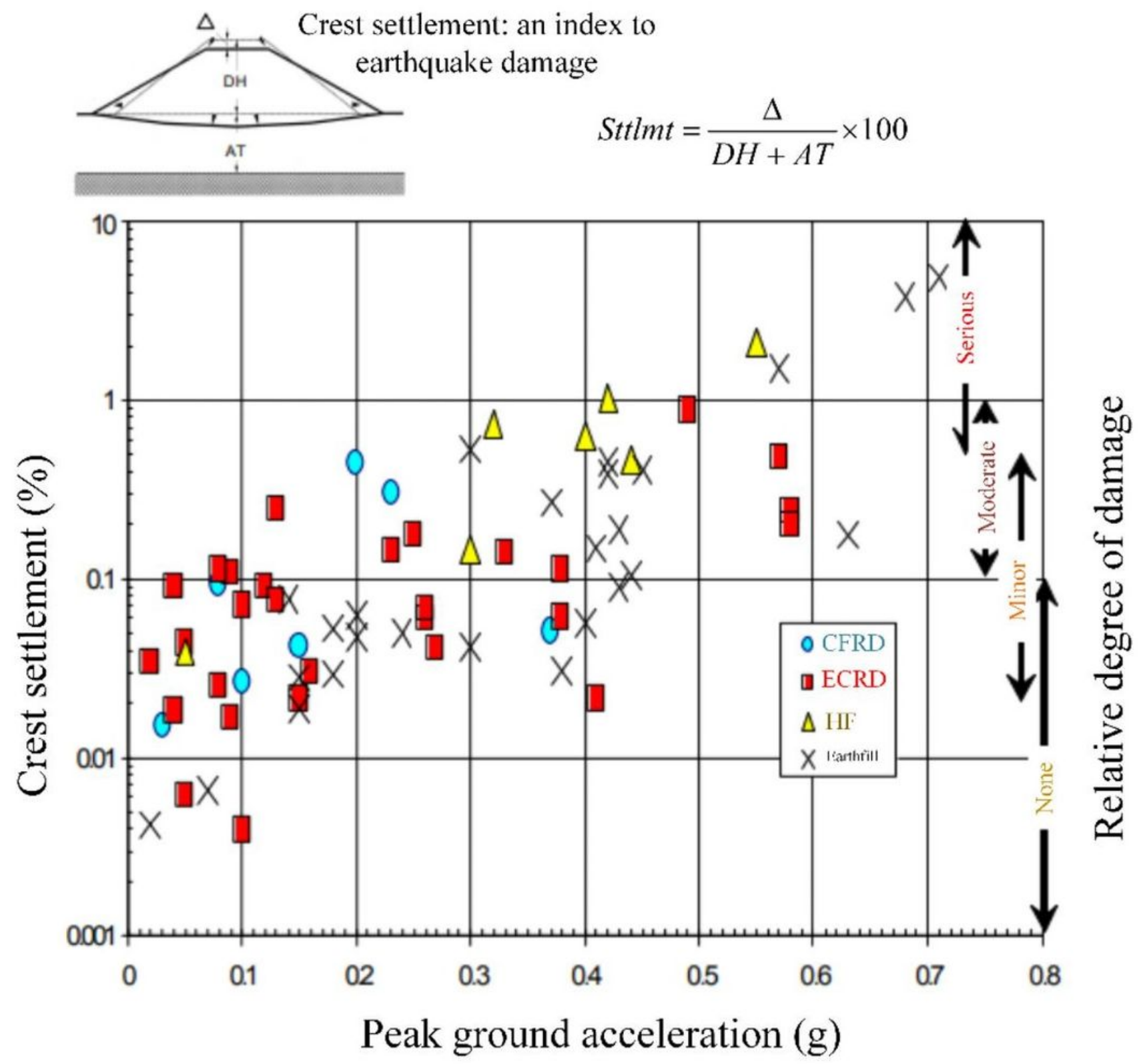

Figure 7

Construction of high ACCRD. 

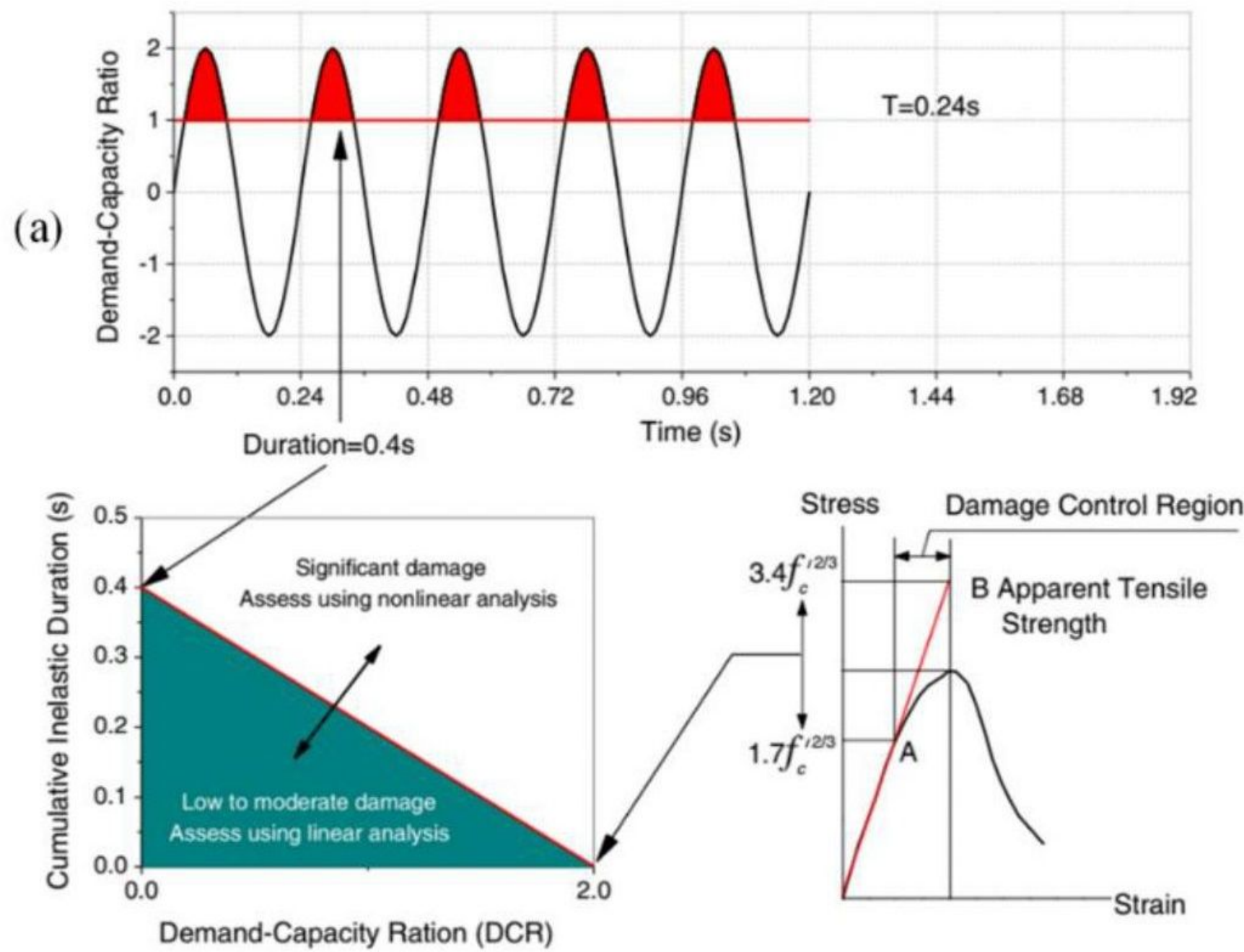

(b)

(c)

Figure 8

Illustration of seismic performance and damage criteria (Ghanaat, 2004). 


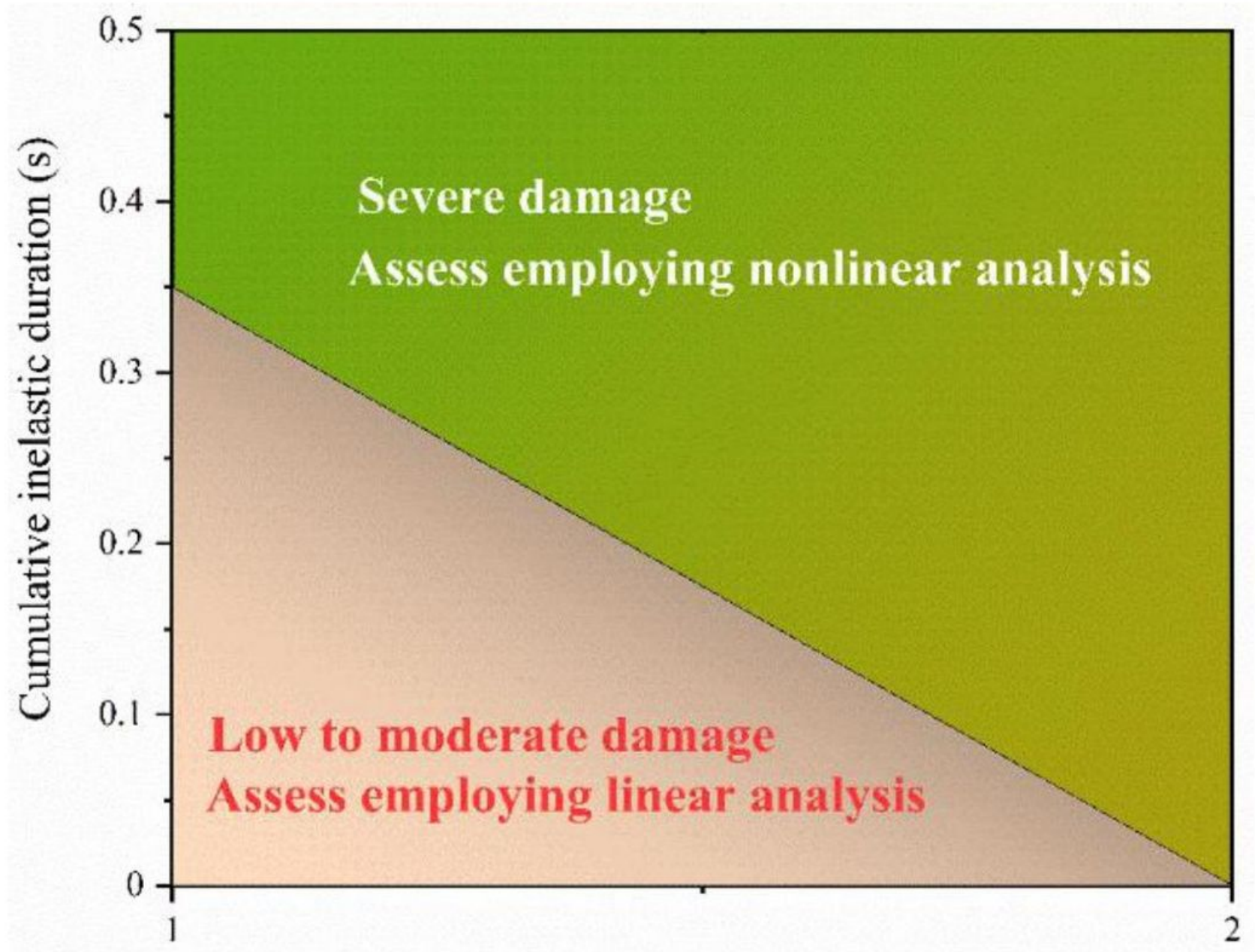

Demand capacity ration (DCR)

\section{Figure 9}

Seismic performance and limit state threshold value of asphalt concrete core.

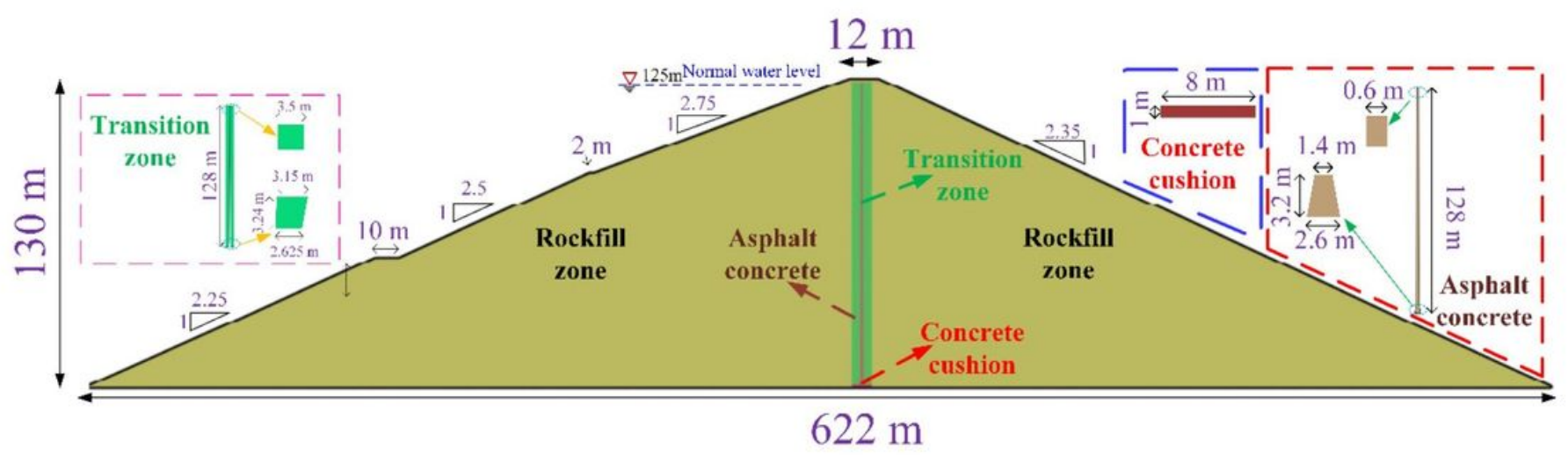

Figure 10 
Construction and design of Dashimen dam: (a) aerial view; (b) cross section

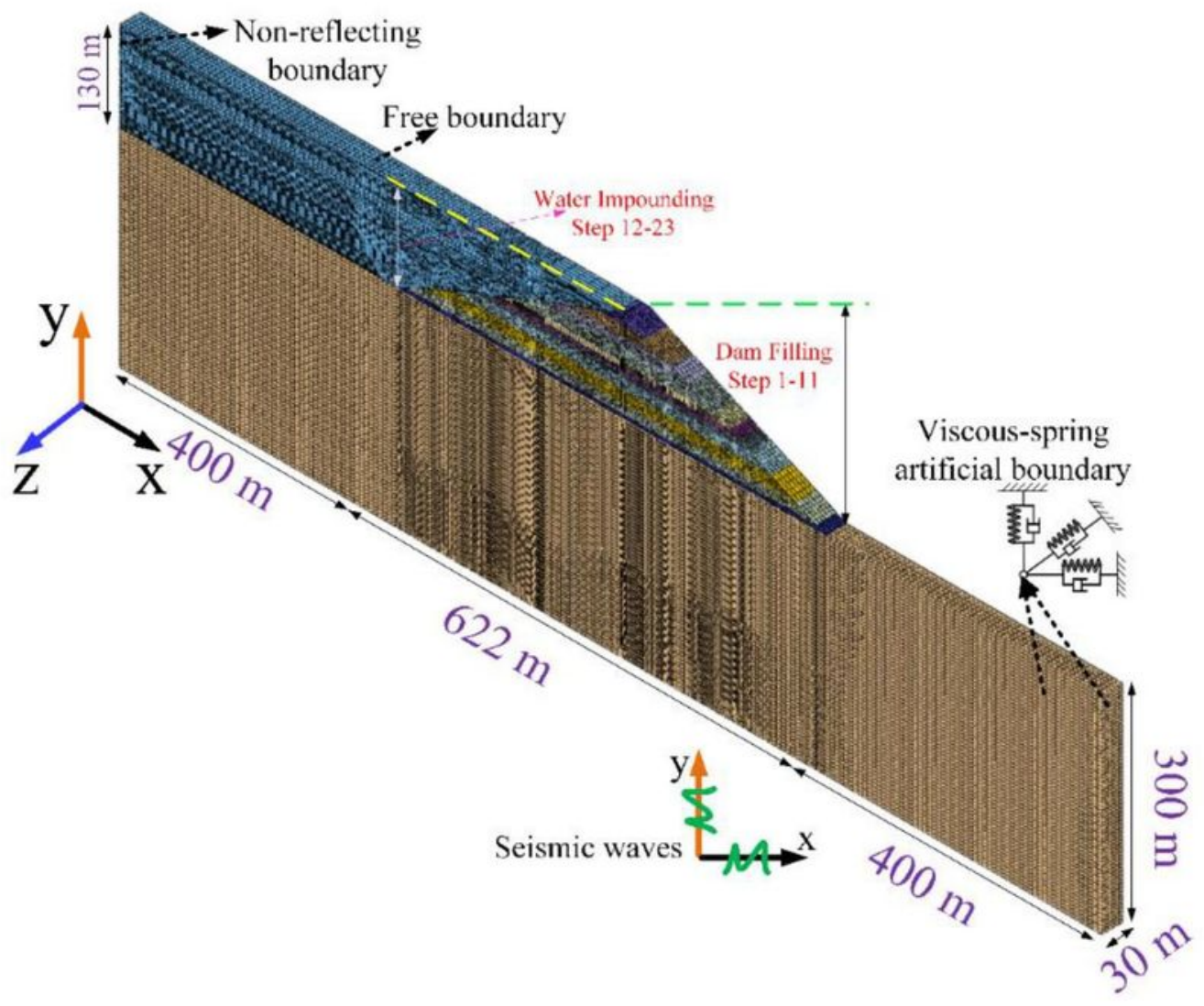

(a)

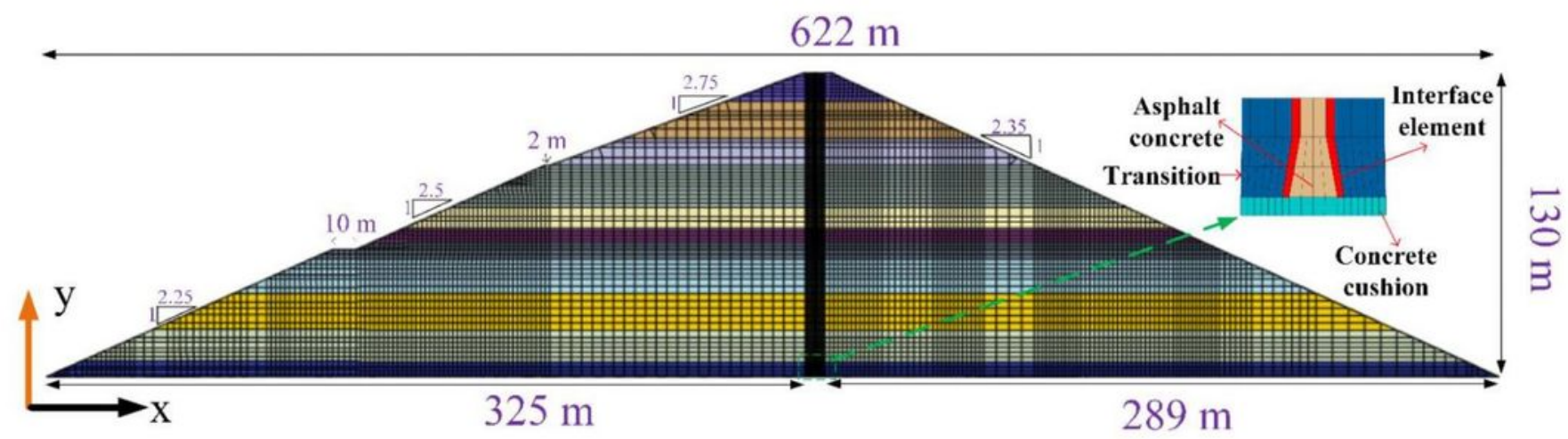

(b)

Figure 11

Details of the high ACCRD - water - foundation FE model. 


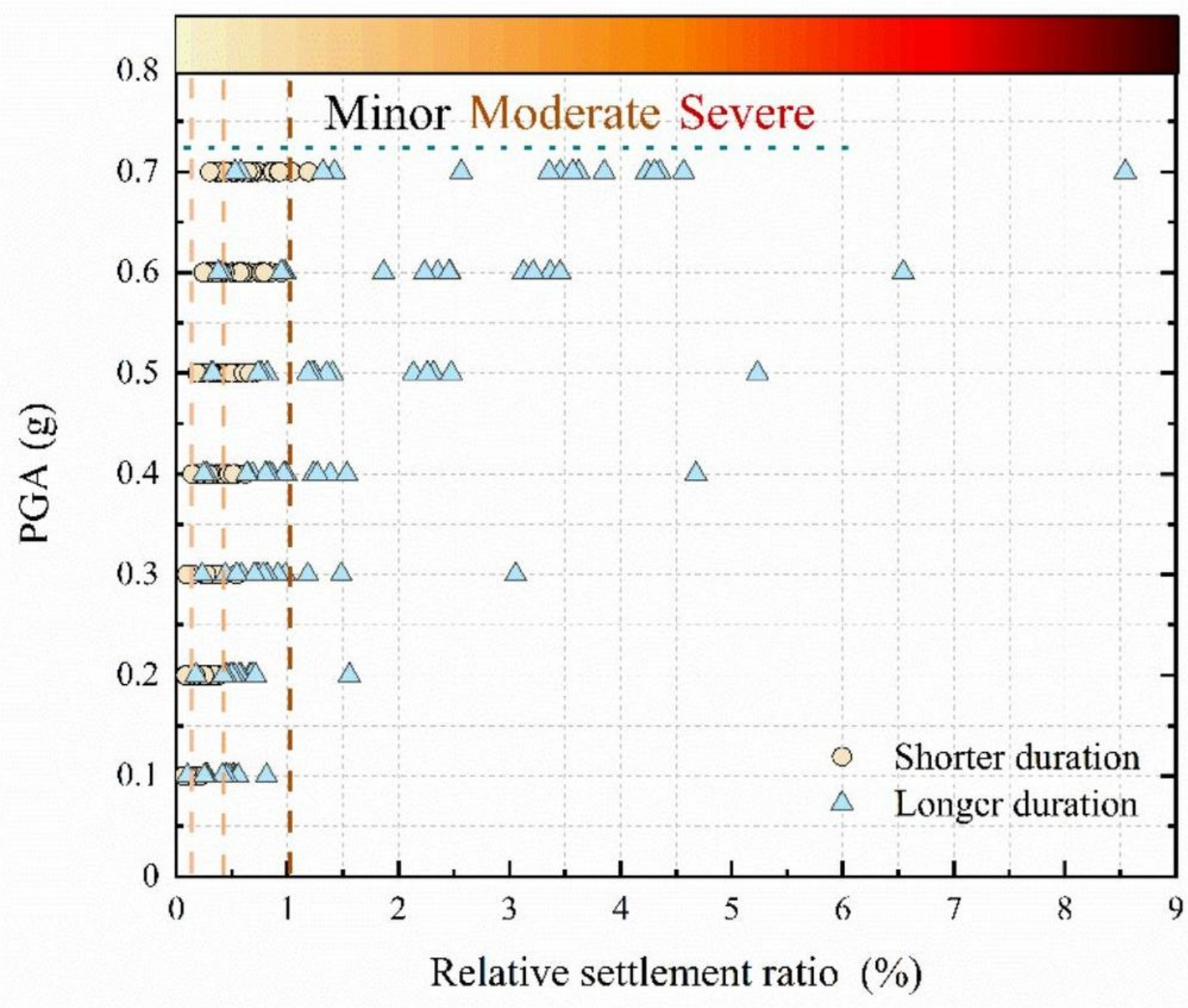

Figure 12

The RSR of multiple strip response under different seismic intensities. 


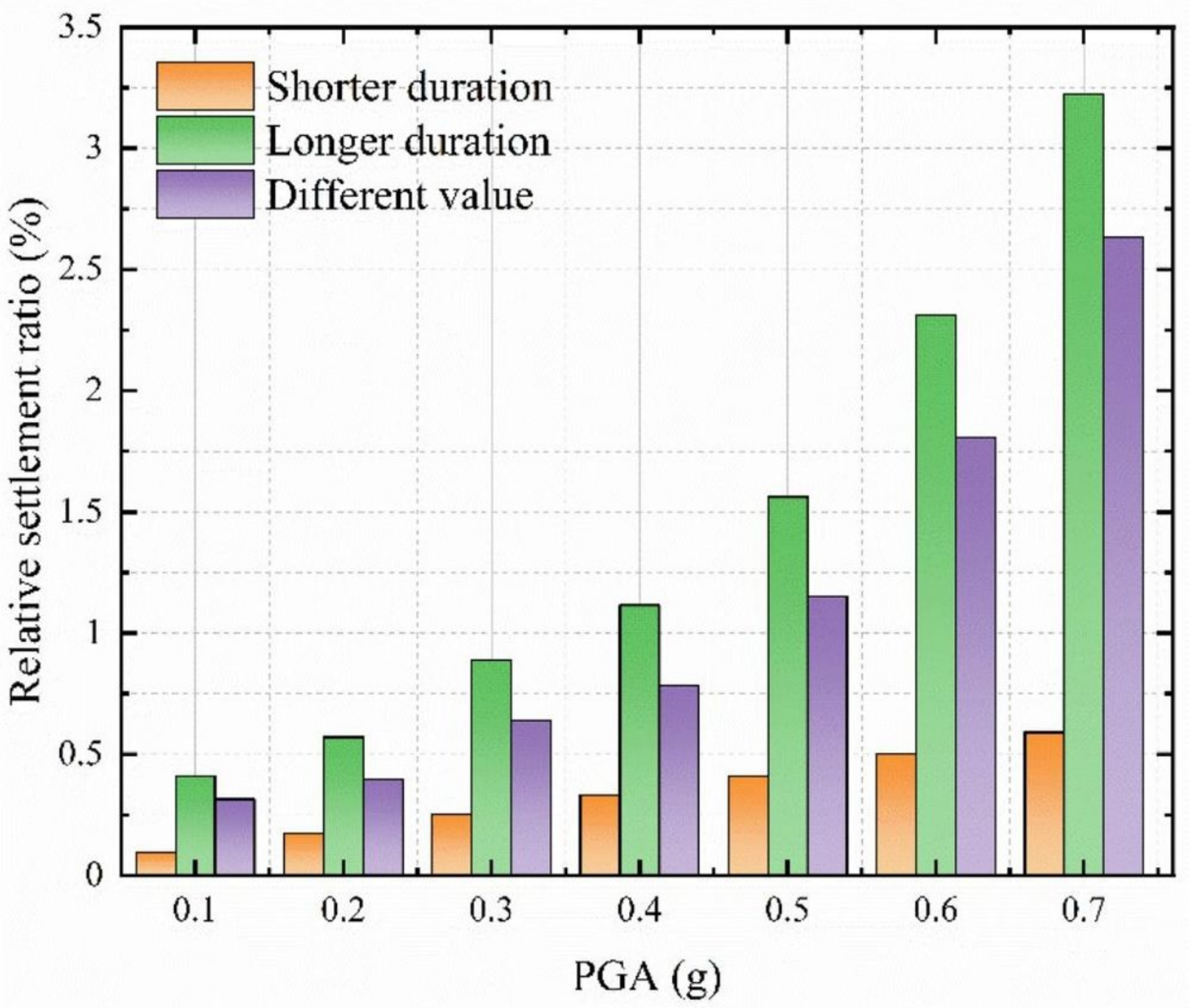

Figure 13

Mean value of RSR. 

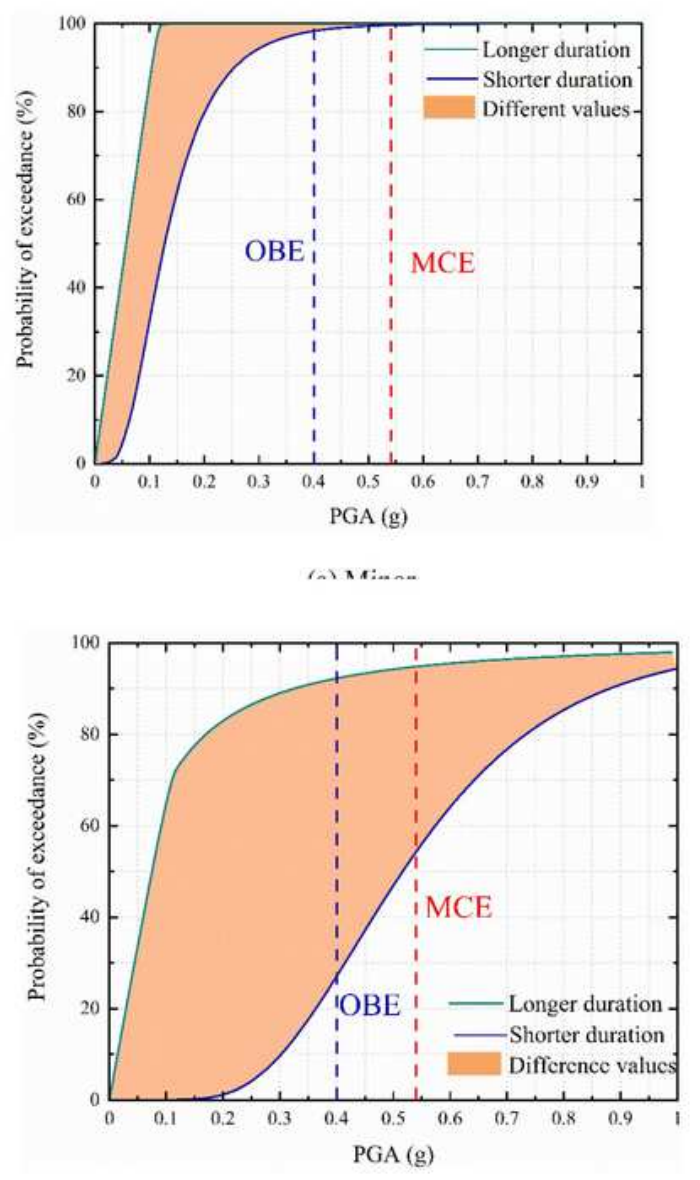

(b) Moderate

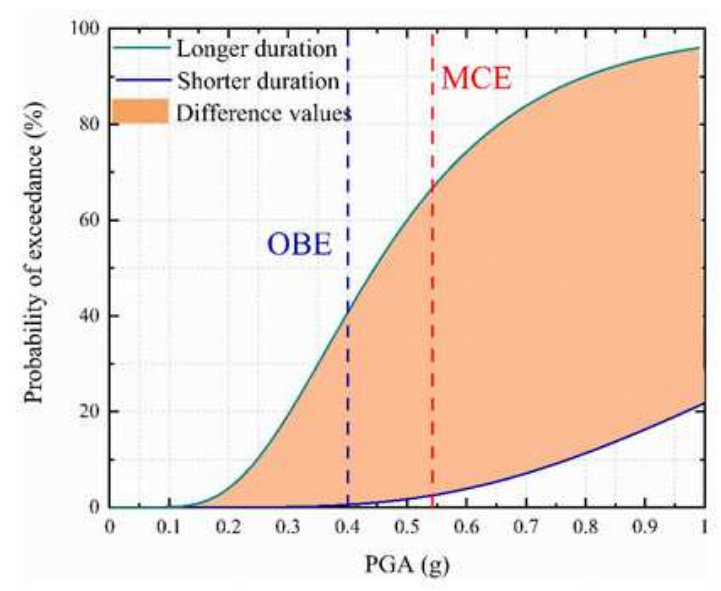

(c) Severe

\section{Figure 14}

Comparison of fragility curves of short - and long - duration GMs for different performance levels: (a) Minor damage. (b) Moderate damage, and (c) Severe damage. 


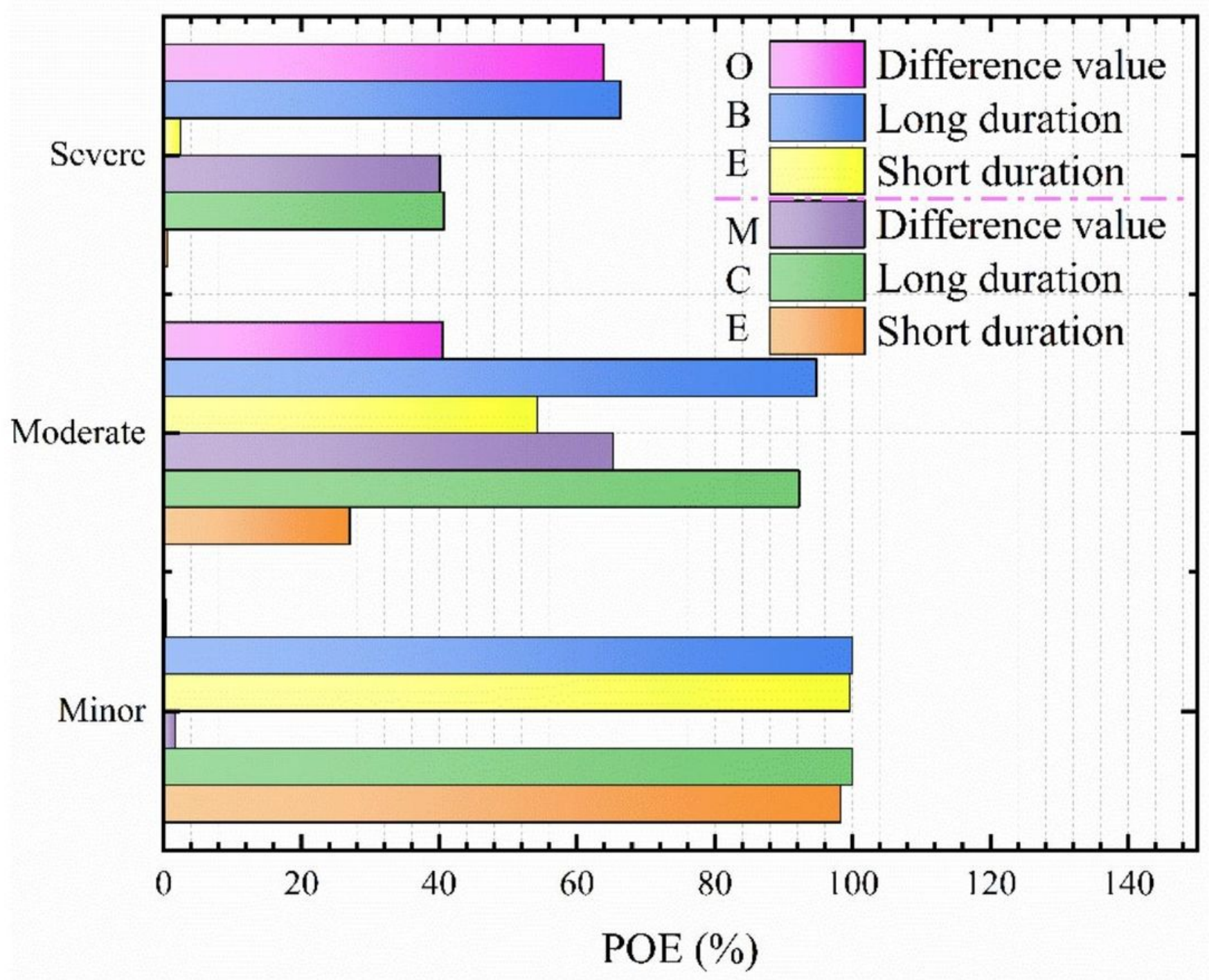

Figure 15

The POE of different performance levels of RSR under OBE and MCE. 


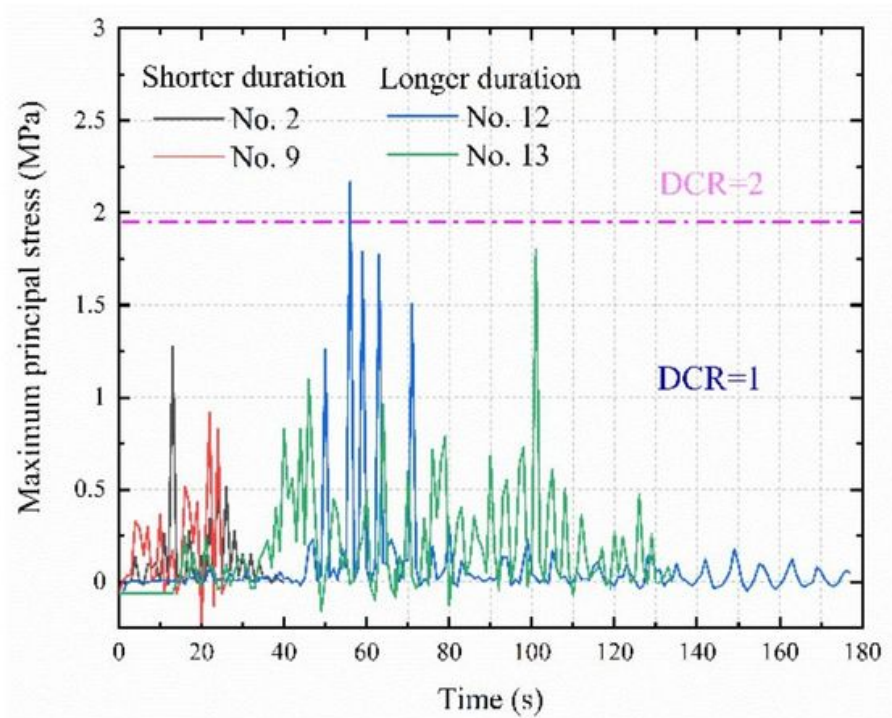

(a) Time histories of maximum principal stress

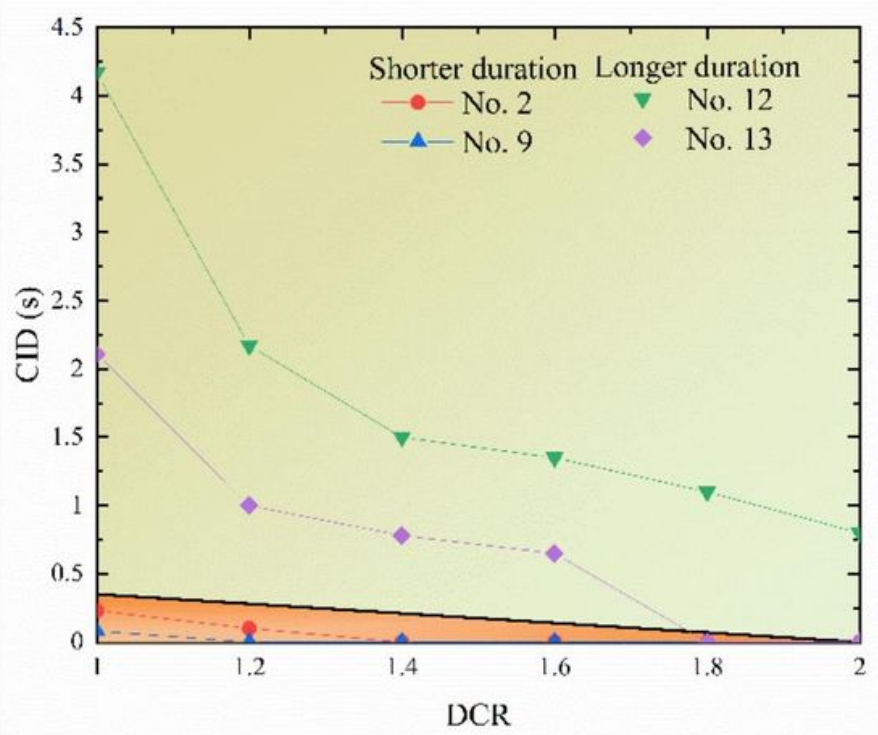

(b) Performance assessment curves

\section{Figure 16}

Time histories of maximum principal stress and performance assessment curves for short - and long duration GMs with a PGA level of $0.5 \mathrm{~g}$. 


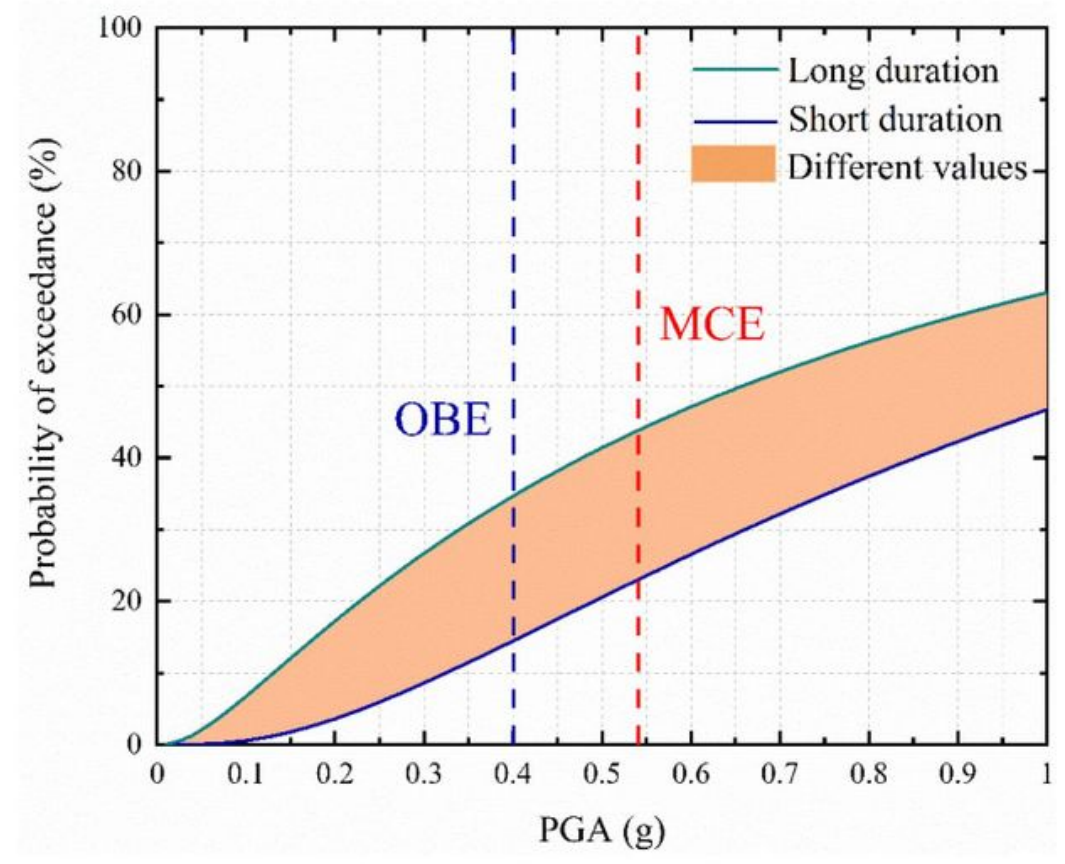

(a) Moderate

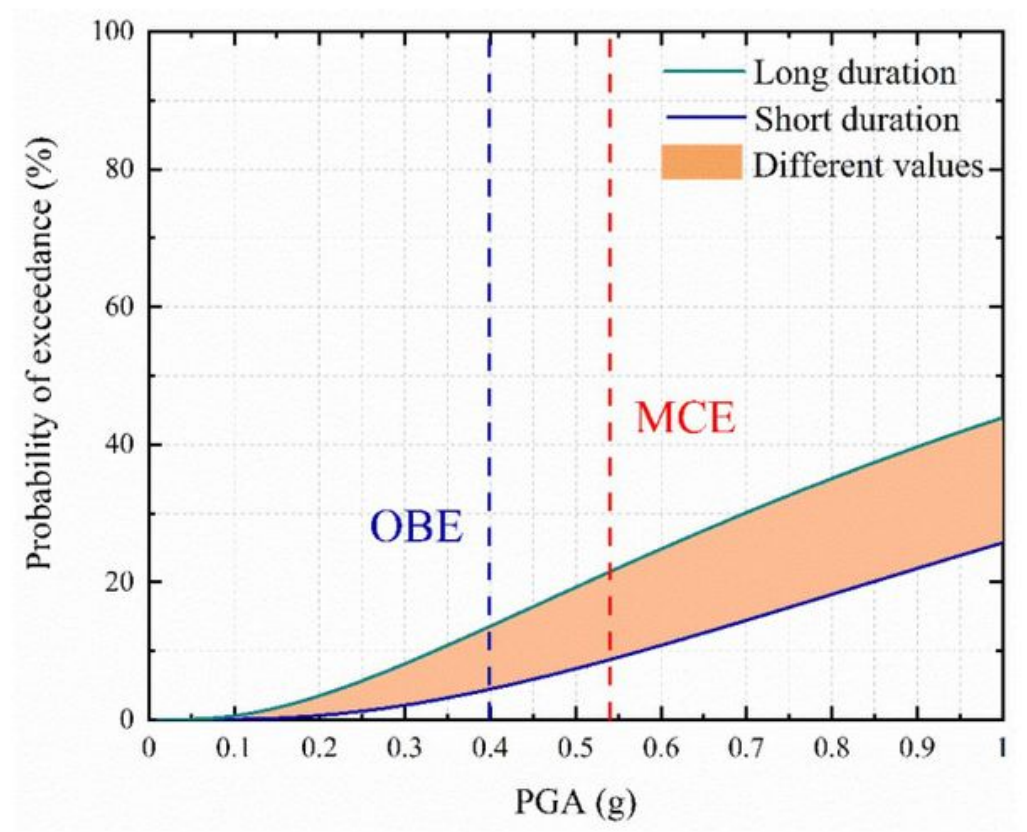

(b) Severe

Figure 17

Seismic fragility curves with short - and long - duration GMs for (a) moderate; (b) severe. 


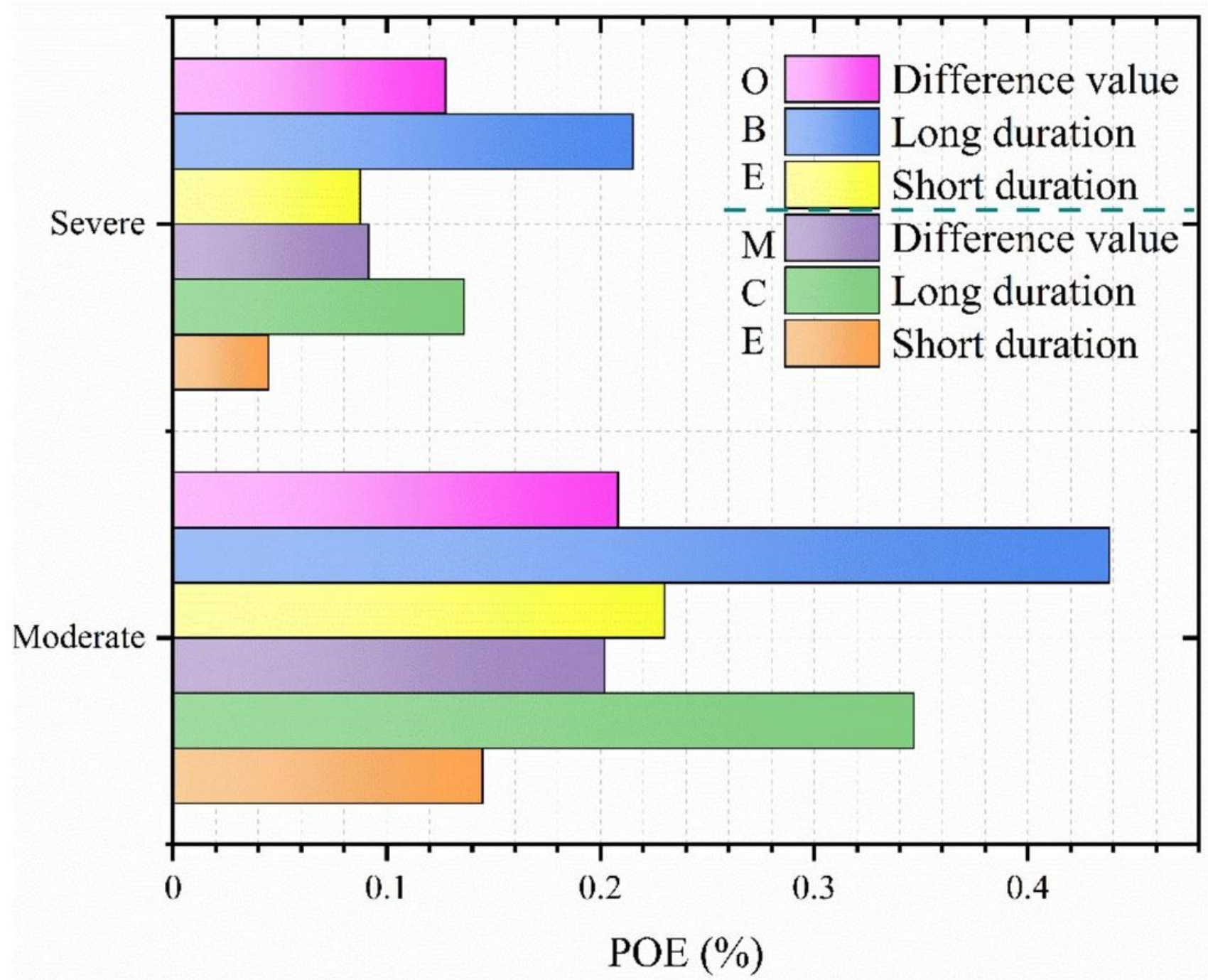

Figure 18

The POE of different performance levels of RSR under OBE and MCE. 